\title{
Inflammation: A key process in skin tumorigenesis (Review)
}

\author{
MONICA NEAGU $^{1-3}$, CAROLINA CONSTANTIN ${ }^{1,3}$, CONSTANTIN CARUNTU $^{4}$, \\ CARMEN DUMITRU ${ }^{3}$, MIHAELA SURCEL ${ }^{1,2}$ and SABINA ZURAC ${ }^{3,5}$ \\ ${ }^{1}$ Immunobiology Laboratory, 'Victor Babes' National Institute of Pathology, 050096 Bucharest; ${ }^{2}$ Faculty of Biology, \\ University of Bucharest, 050107 Bucharest; ${ }^{3}$ Department of Pathology, Colentina Clinical Hospital, 020125 Bucharest; \\ ${ }^{4}$ Department of Physiology, 'Carol Davila' University of Medicine and Pharmacy, 050474 Bucharest; ${ }^{5}$ Department of \\ Pathology, Faculty of Dental Medicine, 'Carol Davila' University of Medicine and Pharmacy, 050474 Bucharest, Romania
}

Received August 7, 2018; Accepted October 2, 2018

DOI: $10.3892 / \mathrm{ol} .2018 .9735$

\begin{abstract}
The extremely delicate shift from an inflammatory process to tumorigenesis is a field of major scientific interest. While the inflammation induced by environmental agents has

Correspondence to: Dr Monica Neagu, Immunobiology Laboratory, 'Victor Babes' National Institute of Pathology, 99-101 Splaiul Independentei, 050096 Bucharest, Romania

E-mail: neagu.monica@gmail.com
\end{abstract}

Abbreviations: ROS, reactive oxygen species; Th, T helper; Tregs, regulatory T cells; IL, interleukin; CTLs, cytotoxic T lymphocytes; LCs, Langerhans cells; GM-CSF, granulocyte-macrophage colony-stimulating factor; TNF, tumor necrosis factor; $\mathrm{MSH}$, melanocyte stimulating hormone; CXCL, chemokine (C-X-C motif) ligand; PGE2, prostaglandin E2; IFN, interferon; TGF, transforming growth factor; ASC, apoptosis-associated speck-like protein; AIM2, absent in melanoma 2; NLR, NOD-like receptor; NLRP, NOD-like receptor with pyrin; NLRC, NOD-like receptor with caspase recruitment domain; BCC, basal cell carcinoma; SCC, squamous cell carcinoma; CARD, caspase recruitment domain; MCs, mast cells; EMT, epithelial-mesenchymal transition; NMSC, non-melanoma skin cancer; HMGB1, high-mobility group box-1; RAGE, receptor for advanced glycation end products; VDR, vitamin D receptor; PCNA, proliferating cell nuclear antigen; iNOS, inducible nitric oxide synthase; COX-2, cyclooxygenase-2; NF- $\kappa$ B, nuclear factor- $\kappa \mathrm{B}$; ER, endoplasmic reticulum; TLR, Toll-like receptor; MAP kinase, mitogen-activated protein kinase; AP-1, activator protein-1; IRF, interferon regulatory factor; AK, actinic keratosis; MMPs, matrix metalloproteinases; ECM, extracellular matrix; RDEB, recessive dystrophic epidermolysis bullosa; IKK2, IKK $\alpha$, inhibitor of NF- $\mathrm{B}$ kinase subunit $\beta$; GFAP, glial fibrillary acidic protein; PAD2OE, MMTV-FLAG-hPAD2; STAT3, signal transducer and activator of transcription 3; NK, natural killer; Smad2, SMAD family member 2; SMA, small worm phenotype; MAD, mothers against decapentaplegic; Nrf2, NF-E2-related factor 2; H-ras, V-Ha-ras Harvey rat sarcoma viral oncogene homolog; IFE, inter-follicular epidermis; HF, hair follicle; K15-KRASG12D, mouse model with mutations in oncogene KrasG12D (activation) and in Smad4 (deletion), in stem cells expressing keratin $15\left(\mathrm{~K} 15^{+}\right)$; ETAR, endothelin A receptor; LGR5, leucine-rich repeat-containing G-protein coupled receptor 5; Sox9, SRY-related HMG-box family of transcription factors; Wnt, wingless-related integration site; PTK6, protein tyrosine kinase 6; well known underlying mechanisms, less is known concerning the oncogenic changes that follow an inflammatory chronic status in the tissue microenvironment that can lead to pro-tumorigenic processes. Regardless of the origin of the environmental factors, the maintenance of an inflammatory microenvironment is a clear condition that favors tumorigenesis. Inflammation sustains the proliferation and survival of malignant transformed cells, can promote angiogenesis and metastatic processes, can negatively regulate the antitumoral adaptive and innate immune responses and may alter the efficacy of therapeutic agents. There is an abundance of studies focusing on molecular

WBCs, white blood cells; VDR, vitamin D receptor; SNP, single-nucleotide polymorphism; CYP24A1, cytochrome P450 family 24 subfamily A member 1; uPAR, urokinase plasminogen activator receptor; NSAID, non-steroidal anti-inflammatory drugs; IF, immune infiltrate; TILs, tumor infiltrating lymphocytes; DCs, dendritic cells; SLN, sentinel lymph node; CDKN1A, cyclin-dependent kinase inhibitor; BMP7, bone morphogenetic protein 7; MDSCs, myeloid-derived suppressor cells; Mo-MDSCs, monocytic MDSCs; PMN-MDSCs, polymorphonuclear MDSCs; Met, HGF receptor; PBMCs, peripheral blood mononuclear cells; CCL, chemokine C-C motif ligand; MHC, major histocompatibility complex; PD-L1, programmed death-ligand 1; CTLA, cytotoxic $\mathrm{T}$ lymphocyte antigen; TAB, tumor associated B cells; MUC18, MCAM melanoma cell adhesion molecule or CD146; Ig, immunoglobulin; KARs, killer activating receptors; KIRs, killer inhibitory receptors; FasL, first apoptosis signal receptor ligand; TRAIL, TNF-related apoptosis-inducing ligand; IDO, indole amine 2,3-dioxygenase; VEGF, vascular endothelial growth factor; $\mathrm{LDH}$, lactate dehydrogenase; S100B, S100 calcium binding protein B; TIMP1, tissue inhibitor of metalloproteinase 1; CRP, C-reactive protein; OS, overall survival; MSS, melanoma-specific survival; M1c, metastasis to non-CNS visceral sites; M1a, metastasis to skin, soft tissue including muscle, and/or non-regional lymph node; M1b, metastasis to lung with or without M1a sites of disease; ALCAM, activated leukocyte cell adhesion molecule; MIA, melanoma inhibitory activity; APRP, acute phase reactant protein; MALDI-TOF, matrix-assisted laser desorption/ionization-time of flight

Key words: tumorigenesis, non-melanoma skin cancer, melanoma, inflammation, inflammasome, immune cells 
pathways that trigger inflammation-mediated tumorigenesis, and these data have revealed a series of biomarkers that can improve the diagnosis and prognosis in oncology. In skin there is a clear connection between tissue destruction, inflammation and tumor onset. Inflammation is a self-limiting process in normal physiological conditions, while tumor is a constitutive process activating new pro-tumor mechanisms. Among skin cancers, the most commonly diagnosed skin cancers, squamous cell carcinoma and basal cell carcinoma (BCC) have important inflammatory components. The most aggressive skin cancer, melanoma, is extensively research in regards to the new context of novel developed immune-therapies. In skin cancers, inflammatory markers can find their place in the biomarker set for improvement of diagnosis and prognosis.

\section{Contents}

1. Introduction

2. Non-melanoma tumors: squamous cell and basal cell skin carcinomas

3. Inflammatory platform in melanoma: reshaping discoveries

4. Inflammatory-related molecules in melanoma: the pattern of inflammatory molecules in melanoma tissue

5. Conclusion

\section{Introduction}

As the largest organ, skin interacts with various environmental factors (1), shields the organisms from radiation, protects it from mechanical pressure and creates one of the main barriers against pathogens (2). Among the main environment aggressors, the UV radiation (UVA and UVB) from the sun induces several biological effects, high DNA damage and reactive oxygen species (ROS) generation. These alterations can induce inflammation and can further initiate tumorigenesis $(3,4)$. ROS and damaged DNA can activate intracellular protein complexes such as inflammasomes (5). Stimulated keratinocytes, the main skin cellular population, along with melanocytes and resident dendritic cells (DCs) and Langerhans cells (LCs), secrete cytokines with pro-inflammatory action (6), and these molecules modulate innate and adaptive immune responses (7). All the immune-related molecules, cytokines, chemokines and non-immune molecules, such as growth factors have both paracrine and autocrine effects upon the microenvironment and design the local millieu that initiates and then regulates local inflammation or can lose control, consequently favoring the process of tumorigenesis (8). Inflammation has acute and chronic stages, but its link to tumorigenesis is carried out by chronic inflammation. While acute inflammation is governed by T-helper (Th)1-polarized T lymphocytes attracted by innate immune cells, secreting mainly antitumor immune molecules such as interleukin (IL)-2 and interferon (IFN)- $\gamma$, chronic inflammation is controlled by regulatory $\mathrm{T}$ cells (Tregs), Th2 cells, that secrete pro-tumorigenic factors [e.g., IL-4, IL-6, IL-10, IL-13, transforming growth factor (TGF)- $\beta$ ]. T cell populations that attract and activate B cells thus favor tumorigenesis and anergize cytotoxic T lymphocytes (CTLs) (9).
In this chronic inflammatory milieu, cells and molecules interact and pro-tumoral microenvironment is sustained $(10,11)$. In skin, as this organ is subjected to a myriad of environmental factors, this chronic inflammatory condition can trigger various processes underlying tumorigenesis affecting the cell components of its structure. We will focus herein on the inflammatory portrait of non-melanoma skin cancer (NMSC) and melanoma cancer, as complex molecular networks that can be both triggers of tumorigenesis and therapeutic targets.

Inflammasomes. There are several non-immune cells that participate in the portrait of inflammation. Various agents can activate the main cellular component of the skin, the keratinocytes. Subsequent to stimulation, these cells secrete pro-inflammatory cytokines (6), regulating both innate and adaptive immunity (7). Keratinocytes, and in addition to these cells and lesser in number, melanocytes and skin resident DCs (LCs), secrete immune-related molecules (e.g., cytokines, and growth factors) that create a local microenvironment depicting inflammation and further tumorigenesis (12). Keratinocytes can play a dual role in $\mathrm{T}$ cell activation. Hence, by the secretion of IL-1, granulocyte-macrophage colony stimulating factor (GM-CSF), tumor necrosis factor (TNF)- $\alpha$, IL-6, IL-7, IL-12, IL-15, IL-18, an upregulation of T cell functions can be achieved. IL-1R $\alpha$, IL-10, $\alpha$-melanocyte stimulating hormone $(\alpha-\mathrm{MSH})$, chemokine (C-X-C motif) ligand 10 (CXCL10), contra IL-1, prostaglandin E2 (PGE2) secreted by keratinocytes can downregulate $\mathrm{T}$ cell functions. In contast, $\mathrm{T}$ cells can produce IFN- $\alpha$, IL-17 and IL-4 that affect the functions of keratinocytes (13). Fig. 1 shows the keratinocyte-T lymphocyte interaction in the skin, interaction mediated by cytokines and chemokines.

Another cell that is regarded as a by-stander cell in the skin, the sebocyte, was recently reported as being involved in maintaining the skin's inflammatory milieu. These cells encompass the pilosebaceous unit and secrete skin moisturizing lipids. Yet, they also secrete chemokines and cytokines and act in response to several pro-inflammatory stimuli and bacteria. Recently it was reported that $\mathrm{CD} 4^{+} \mathrm{IL}-17^{+} \mathrm{T}$ cells are in contact with sebocytes in acne lesions. Sebocyte secrete chemokines (e.g., CXCL8) that call upon neutrophils, monocytes and T lymphocytes. Cytokines (e.g., IL-6, TGF- $\beta$, IL-1 $\beta$ ) secreted by sebocytes induce the differentiation of CD $4{ }^{+} \mathrm{CD} 45 \mathrm{RA}^{+}$naive $\mathrm{T}$ cells into Th17 cells without affecting memory $\mathrm{T}$ cells. Practically, Mattii et al presented the first report that proves human sebocytes are actively involved in the skin's inflammatory processes. Furthermore, as the main regulated cell is Th17 and, because it is known that the loss of this regulatory $\mathrm{T}$ lymphocyte is linked to chronic inflammation, sebocyte activity can be associated with pro-tumorigenesis processes (14).

UVA and UVB radiation directly affects skin, and this injury leads to DNA damage and ROS production. Furthermore, these elements induce an inflammatory response and, if regulatory mechanisms are surpassed, they can trigger pro-tumorigenesis mechanisms $(3,15)$. Moreover in this process, complex protein platforms designated as inflammasomes are activated (16) and the link between chronic inflammation and distorted inflammasome activity is associated with skin disorders including cancer $(8,17)$. Inflammasomes are complexes formed from a 


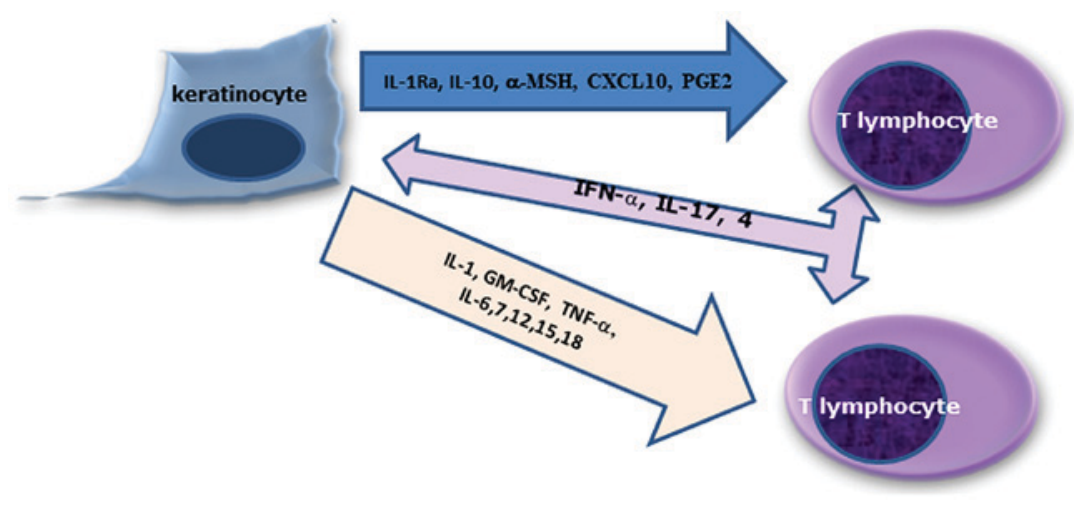

Figure 1. Relation between keratinocytes and T lymphocytes. Keratinocytes secrete upregulatory cytokines and chemokines IL-1, GM-CSF, TNF- $\alpha$, IL-6, IL-7, IL-12, IL-15 and IL-18, and downregulatory ones, IL-1R $\alpha$, IL-10, $\alpha$-MSH, CXCL10 and PGE2. T cells produce IFN- $\alpha$, IL-17 and IL-4 that influence keratinocyte functions. Keratinocyte chemoattractant cytokines influence T-cell trafficking: IL-1, IL-8, CCL27, CCL5, CCL17, CXCL10, MIG, IP9, CCL20.

cytoplasmic sensor, an adaptor known as apoptosis-associated speck-like protein (ASC) and pro-caspase-1 (5) (Fig. 2). Actually inflammasomes are a large family that is characterized by their sensors [e.g., absent in melanoma 2 (AIM2), pyrin, NOD-like receptor with pyrin (NLRP)1, NLRP3, NOD-like receptor with caspase recruitment domain (NLRC)4] (18).

When UV radiation hits the skin, within sebaceous lipids, squalene is oxidized and initiates inflammatory processes (19) thus acting as inflammasome activating danger signal (20). The most frequent type of inflammasome, NLRP3, is increased in human BCC along with higher IL-1 $\beta$ levels and caspase-1 activation compared to normal skin (21). Pannexin-1 channels involved in keratinocyte differentiation that can induce inflammasome activation (22), were also identified in melanocytes and were found to be upregulated throughout melanoma progression (23). NLRP1 is strongly expressed in human skin as compared to other NLRs (24). At the genetic level, polymorphisms detected in NLRP1/NLRP3 (25) and in inflammasome-related genes [e.g., caspase recruitment domain (CARD)8, IL-1 $\beta$ and IL-18) were found to be associated with skin melanoma, related to both susceptibility and progression (26). The inflammasome involvement was demonstrated to be correlated with melanoma stages. Hence, cells isolated from late stage human melanomas generate spontaneously IL- $1 \beta$ without stimulation, showing auto-inflammatory characteristics, namely gain-of-function mutations in NLRP3. This study has pointed out that, IL-1 $\beta$ constitutive secretion can be clearly linked to the aggressiveness of melanoma (27). The ASC component of the inflammasome is involved in tumorigenesis in metastatic melanomas, while in primary melanoma, it inhibits cancer cell growth (28). Of note, the role of ASC is different in various cells involved in the link between inflammation and tumorigenesis. ASC exhibits a tumor-suppressor function in keratinocytes, while in myeloid cells are pro-tumorigenic (29). Collectively, recent information suggests that among all NLRPs, NLRP1 is the main inflammasome sensor in human skin $(24,30)$. In skin models it was shown that cytokine stimulation using IL-1 $\alpha$, IL-1 $\beta$ and IL-18 induces epidermal hyperplasias (24), an adjacent characteristic of tumor tissue.

Inflammation leading to tumorigenesis. In normal homeostasis of the skin, inflammation is self-limiting, while tumorigenesis has a constitutive activation pathway (31). Long-term accumulation of inflammatory factors in the skin tissue (e.g., cytokines/chemokines) may finally lead to an immunosuppressive microenvironment that favors tumorigenesis. Cytokines are produced in the skin by resident cells, namely keratinocytes, LCs, melanocytes, mast cells (MCs) and macrophages, whereas recruited cells, such as neutrophils, eosinophils and lymphocytes add secreted cytokines to the tissue microenvironment (32). Upon cellular activation, cytokines are rapidly secreted acting within the tissue, in both paracrine and autocrine manner. In a prolonged inflammatory status, cytokine synthesis and production are constantly enhanced, the auto-regulatory loop is hindered and acts upon both neighboring cells as well as upon distant cell populations. The action of cytokines is vast as cytokine receptors can be homologous; namely various cytokines lead to multidirectional effects. Moreover, various cytokines can address the same receptor having a synergistic effect on one cell type, while acting antagonistically on another cell type. The cytokine cascade is different for acute and chronic inflammation (Fig. 2) and while one has antitumoral characteristics, the other one sustains tumorigenesis (33), tumor cell migration and cancer metastasis mechanisms (34).

There are various cell populations that intimately interact (epithelial, mesenchymal and immune cells) for the inflammatory process to develop and if chronically induced, further triggers tumorigenesis. Epithelial-mesenchymal transition (EMT) is a process involved in tumorigenesis mechanisms. It is actually a process through which epithelial cells lose cell polarity and cell-cell adhesion, and are able to migrate and invade other tissues becoming mesenchymal stem cells (35). While in physiological wound healing, EMT induction (36) is beneficial, as epidermal keratinocytes acquire migratory phenotypes for wound re-epithelialization (37), in tumors, EMT is uncontrolled and epithelial cells acquire oncogenic mutations (38).

Another cell population that can contribute to the link between inflammation and tumorigenesis in the skin is the fibroblast. During wound healing fibroblasts deposit collagen in excess (fibrosis), fibrotic connective tissue being actually a pro-tumorigenesis microenvironment (39).

All the recent reports state that there is a clear relationship between chronic tissue damage, inflammation and cancer. At 
chronic inflammation sites, triggered by various intrinsic and extrinsic factors, tumors can develop. A hindered regulatory loop for an efficient inflammation process would lead toward tumorigenesis. Once the program for tumorigenesis is installed, continuous inflammation supports metastatic progression (31).

\section{Non-melanoma tumors: squamous cell and basal cell skin carcinomas}

Worldwide, NMSC is the most frequent type of skin cancer in Caucasian populations, registering an increased incidence in the last 40 years. This rapid increase is based on UV radiation exposure accounting for $90 \%$ of NMSC cases. Although the incidence of other malignancies has stabilized or even declined, the incidence of NMSC has increased constantly with a younger patient age at diagnosis, representing a main public health concern (40).

Although NMSC is not a main life-threatening disease, the direct social costs involved in such a widely spreading disease are high. Studies concerning the early diagnosis along with prevention and therapy are the main domains that are constantly evolving in NMSC. Etiopathogenic mechanisms are intensively studied and, within, a special focus has been given to the mechanisms that link inflammation and skin tumorigenesis. Basal cell carcinoma (BCC) and squamous cell carcinoma (SCC) are the most frequent NMSC, registering the highest world incidence in Auckland where rates were 425 for SCC and 1,177 for BCC per 100,000 individuals per year (41). Histological and immunohistological evaluation of SCC and $\mathrm{BCC}$ has shown that peritumoral inflammatory reaction is diverse in intensity and distribution, proving the complexity of the immune cells and tumor cells. In SCCs, the inflammatory reaction is increased in comparison to BCC. Inflammatory immune cells such as T-lymphocytes, macrophages and MCs are in direct contact with tumor cells, sustaining intercellular interaction mechanisms (42).

In addition to immune cells, pro-inflammatory and tumor-promoting molecules have been reported in BCC and SCC. Recently, high-mobility group box-1 (HMGB1) protein and the receptor for advanced glycation end products (RAGE) have been studied in NMSC. RAGE was reported as being upregulated in SCC along with advanced stage cutaneous melanoma with poor prognosis. In BCC and SCC, extracellular expression of HMGB1 was reported to be released by necrotic tumor cells but further studies are warranted (43).

Other new associated inflammatory proteins are the galectin family involved in various pathologies related to skin through their intracellular and extracellular mechanisms. Skin structural cells such as keratinocytes, melanocytes, fibroblasts and endothelial cells express galectins. Immune cells resident in the skin, such as DCs, lymphocytes and macrophages express these proteins as well. Non-malignant skin pathologies with high inflammatory background, such as atopic dermatitis, psoriasis, contact dermatitis and wound healing are associated with an increased galectin expression. But recently, skin cancers have been demonstrated to express these known inflammatory proteins involved in regulatory mechanisms (44). Patterns of galectin-3 expression in BCC and SCC were evaluated in relation to cellular differentiation. The study revealed that there is a specific pattern where decreased nuclear galectin-3 expression and cytoplasmic immunoreactivity can be factors involved in SCC tumor aggressiveness (45).

Specific inflammatory actors, such as IL-17 and IL-22 were recently studied in SCC and BCC. In both NMSCs, $\mathrm{T}$ lymphocytes that secrete IL-17 and IL-22 are abundant. In BCC and SCC cell lines, proliferation and migration abilities were significantly increased by in vitro IL-17 and IL-22. Furthermore, IL-17 alone or combined with TNF- $\alpha$, induced the synthesis and production of two known pro-tumor cytokines, IL-6 and IL-8. In animal models IL-17 and IL-22 increased tumor growth proving once more that inflammatory cytokines such as IL-22 and IL-17 in NMSC promote a tumorigenesis microenvironment (46).

As skin carcinogenesis induced by UV irradiation is a constant research domain, it was shown that UV activates oncogenes while inactivating tumor-suppressor genes. Inflammatory milieu created by infiltrating immune cells contributes to the chronic inflammation and to the progression of skin tumors (40). In the link between UV irradiation and skin inflammation, a special focus has been developed in the research of vitamin D suggesting that vitamin D receptor (VDR) gene polymorphisms can favor BCC and SCC. During an 11-year follow-up, a recent study has shown that patients with rs2228570, rs927650 and rs1544410 dominance while rs7975232 and rs739837 recessive genotypes were linked to a lower risk to develop BCC. This is one of the few studies that links a genetic VDR specificity to the risk of developing NMSC (47).

In addition to UV irradiation, other factors that induce inflammation and further tumor development have been studied. Hence in a prospective study reported in 2017, QSkin, involving over 40,000 patients, it was shown that for smokers the risk for developing SCC was high without a link with the duration and/or intensity of smoking (48).

In a mouse model of UV carcinogenesis the anti-inflammatory naproxen was tested to evaluate its anti-proliferative action. Naproxen inhibited UVB-induced BCC and SCC reducing both tumor number and volume. The overall anti-proliferative effect was associated with reduced proliferating cell nuclear antigen (PCNA) and cyclin D1 expression and increased apoptosis. All markers that are usually associated with inflammation [e.g., inducible nitric oxide synthase (iNOS), cyclooxygenase-2 (COX-2), nuclear factor (NF)- $\kappa \mathrm{Bp} 65$ ] were decreased. Tumors from treated animals had lower invasiveness with increased E-cadherin expression and reduced expression of EMT markers (e.g., N-cadherin, vimentin, Snail, Twist). In BCC and SCC cells, it was shown that naproxen reduced UVB-induced skin carcinogenesis through reducing endoplasmic reticulum (ER) stress pathways (49).

Another molecule involved in inflammation pathways, Toll-like receptor 4 (TLR4), is involved also in photo-immunosuppression and chemically-induced carcinogenesis. During the switch from normal skin to actinic keratosis (AK), TLR4 appears in keratinocytes and it is enhanced once more when the keratinocyte progresses to SCC. In vitro silencing of TLR4 within keratinocytes blocks UV stress. A TLR4 antagonist, resatorvid, blocks several inflammatory pathways such as NF- $\kappa \mathrm{B}$ and MAP kinase/AP-1 and hinders cytokine expression, including IL-6, IL-8 and IL-10. This effect was reproduced also in animal models (50). 


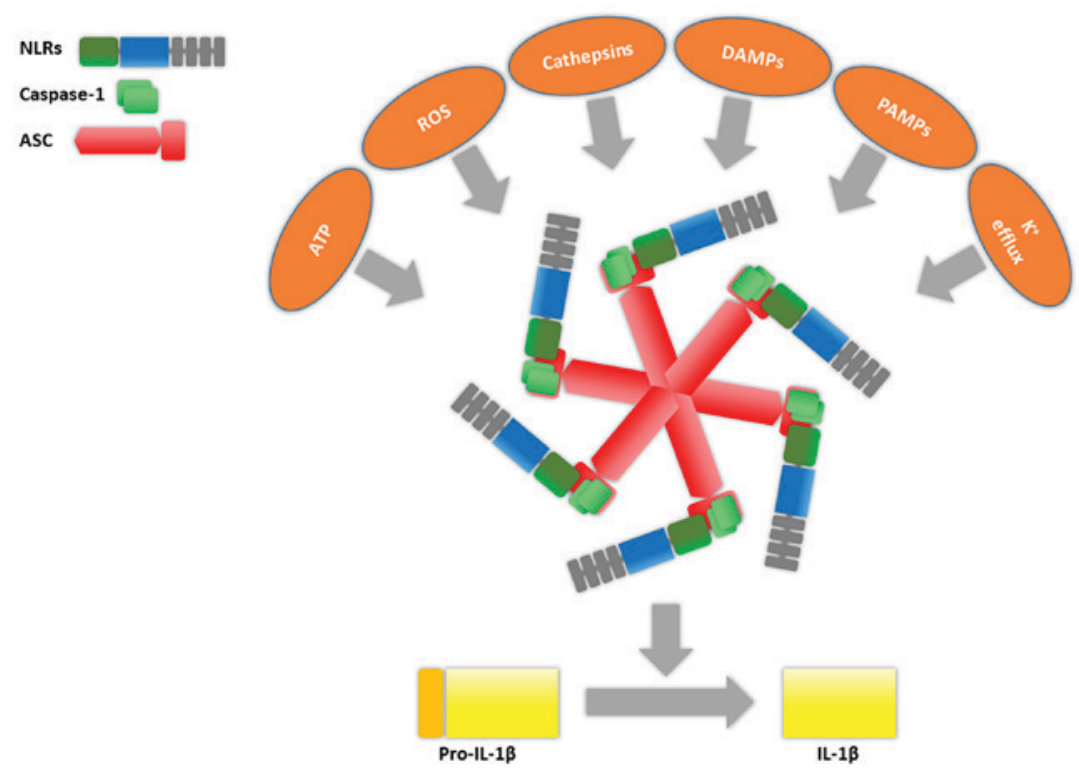

Figure 2. Inflammasome basic structure consists of caspase-1, NLRs and ASC. The specific composition of an inflammasome is dependent on the activator, e.g., ATP, ROS, cathepsins, DAMPs, PAMPs, $\mathrm{K}^{+}$efflux. The main action of the assembled inflammasome is to induce the conversion of pro-IL- $1 \beta$ in IL- $1 \beta$. NLRs, nucleotide-binding oligomerization domain and leucine-rich repeat-containing receptors; ASC, apoptosis-associated speck-like protein; ROS, reactive oxygen species.

Inflammation in NMSC is a hallmark of tumorigenesis and several deregulated pathway conjoin in initiating neoplastic transformation (51).

Inflammation in SCCs. Keratinocytes are the main cells of the epidermis whose deregulated proliferation could initiate NMSCs. Inflammatory pattern associated with carcinogenesis can furbish new therapeutic targets or new inflammatory markers for diagnosis and prognosis $(52,53)$. Proteome profiling of keratinocytes identified 50 proteins related to this type of cell, some of them associated with the immune system [e.g., $\alpha-2$ macroglobulin-like protein-1, $\alpha-2$ macroglobulin-like protein 2 and IFN regulatory factor- 6 (IRF-6)], others involved in differentiation (e.g., dermokine and calmodulin like protein 5) and others involved in motility (e.g., integrin $\beta 4$ ) (54). However the mentioned proteins are deeply regulated by the inflammatory status, hence when keratinocytes were stimulated with IL-1 $\beta, \alpha-2$ macroglobulin like protein- 1 and integrin $\beta 4$ were found to be reduced. IL- $1 \beta$ stimulation increased the $\mathrm{NF}-\kappa \mathrm{B}$ pathway, highly involved in angiogenic and pro-tumorigenic processes. In epidermoid carcinoma cells all of these alterations were also found to support this link between inflammation and carcinogenesis (54).

SCC is the most frequent metastatic NMSC and an inflammation pattern would indicate cancer progression. As stated above, inflammasome proteins are a new expanding research domain. In SCC cell lines upregulation of the AIM2 sensor at both the protein and mRNA levels has been reported. In human SCC samples, tumor-specific expression of AIM2 was noted with low or absent expression in AK and normal skin. Following knockdown of AIM2 in specific tumor cell lines, cellular viability was decreased and apoptosis was increased. Moreover this knockdown decreased the invasive capacity of SCC cell lines associated with the reduction in matrix metalloproteinases (MMPs), MMP1 and MMP13. In vivo inoculated knockdown xenografts displayed a lower rate of tumor growth and vascularization. These experimental results point toward a component of the inflammasome machinery that can be a future therapeutic target (55). Besides MMP supra-expression (MMP1, MMP3, and MMP-9) in human samples it was reported that keratins 6, 16, and 17 are overexpressed in keratinocytes. When collagen type I synthesis is reduced upon UV irradiation, this triggers the TGF- $\beta$ pathway, a cytokine highly involved in inflammatory processes (56-58). Related to the activity of MMP proteins, adherence to the extracellular matrix (ECM) is important in the migratory process of tumor cells. A study published in 2018 focused on the aggressive characteristics of SCC and a series of ECM traits. Using proteomic and histologic tests for human primary SCC tumor tissue, three types of samples were analyzed: non-recurring, non-metastasizing, metastasizing SCC and SCC from patients with recessive dystrophic epidermolysis bullosa (RDEB). Patients with the RDEB genetic disorder harbor mutations that hinder both the function and the amount of type VII collagen and they have a high risk of developing SCC. The most deregulated samples were proven for RDEB and SCC samples that displayed the highest mutational rates with important inflammation and consequent dermal ECM remodeling as tumor set-off factors. High-risk SCC also may display an enhanced bacterial challenge as inflammatory activating factors. This report discloses ECM remodeling as a clear inflammatory trait related to SCC that sustains the increased risk for a worse prognosis of the disease (59). In an RDEB mouse model it was shown that the persistence of chronic wounds leads to SCC development. These non-healing wounds have high TGF- $\beta 1$ expression, enhanced fibrogenesis thus creating a pro-tumorigenic microenvironment (60).

As mentioned in the inflammasome section, ASC mediates the secretion of pro-tumorigenic cytokines. ASC expression in 
human SCC was evaluated in non-metastatic and metastatic SCC. After silencing ASC it was demonstrated that alteration in the activation of innate immune cells can be linked to keratinocyte activity. Restoring ASC induced AIM2 and NLRP3 activation. Thus it was demonstrated that pro-tumorigenic inflammation is actually induced in the tumor cell (61).

$\mathrm{NF}-\kappa \mathrm{B}$ signaling is extremely important for the maintenance of immune equilibrium in epithelial tissues. In a mouse model with IKK2 deletion in GFAP-expressing cells of the epidermis increased expression of TNF was also found in the SCC-type lesions (62).

In another mouse model, overexpression of MMTVFLAG-hPAD2 (PAD2OE) also induced SCC-type lesions. Skin tumorigenesis was associated with inflammation in this mouse model. PAD2OE lesions presented with high inflammatory cell infiltrates and increased nuclear phosphorylated signal transducer and activator of transcription 3 (STAT3). This report proves that benign papillomas can be transformed to SCC lesions when inducing an inflammatory microenvironment (63).

In addition to keratinocytes, a report published in 2017 showed that LCs, resident in the epidermis and in the pilosebaceous structure, are involved in maintaining the physiology of the skin. When an injury occurs, LCs process antigens and circulate to the local lymph nodes and activate $\mathrm{T}$ cells. Thus, LCs can activate immune effector cells for an anti-tumoral immune response. Moreover LCs cooperate with NK lymphocytes controlling the development of SCC. In contrast LCs can also have pro-tumorigenic activity when involved in the activation of $\mathrm{T}$ suppressor lymphocytes, allowing malignant transformation of keratinocytes within SCC (64).

Glycosylphosphatidylinositol-anchored glycoprotein (CD109) is expressed by immune cells, such as T lymphocytes, activated $\mathrm{T}$ lymphoblasts, or non-immune cells including endothelial cells and activated platelets (65), but it is expressed also by human cancers, predominantly SCC. Sunagawa et al demonstrated that CD109-deficient mice display chronic skin inflammation and epidermal hyperplasia. Recently, they showed that in CD109-deficient mice the dermis had a higher level of TGF- $\beta$ protein expression. In keratinocytes, SMAD family member 2 (Smad2) phosphorylation and NF-E2-related factor 2 (Nrf2) expression were enhanced in primary keratinocytes along with reduced apoptosis and DNA damage and reduced $\mathrm{H}$-ras gene mutation frequency. All these data suggest that CD109 deficiency suppresses skin tumorigenesis by enhancing TGF- $\beta / \mathrm{Smad} / \mathrm{Nrf} 2$ pathway activity and decreasing the mutation frequency of the H-ras gene (66).

Mast cells (MCs) have been reported as components of cancer microenvironment in melanoma, BCC, SCC, primary cutaneous lymphomas, haemangiomas and Merkel cell carcinoma. Their role seems to be dual. In several studies they were reported as having pro-tumorigenesis action while in others an anti-tumorigenesis effect. Tumor-associated MCs should be thoroughly investigated in the future for establishing their clear role in skin cancers (67).

As described above, the EMT process can be pro-tumorigenesis, but the occurrence is different in SCC of different origins. SCCs emerging from inter-follicular epidermis (IFE) are well differentiated, while SCC that originates from hair follicle (HF) stem cell-derived frequently exhibit EMT, with an increased metastatic capacity. Therefore,
IFE and HF tumor-initiating cells have different gene networks associated with different biological behavior (68). In the stem cell niches, inflammatory factors can drive pro-tumorigenesis processes. IL-27 can have both pro- and anti-inflammatory properties, and using a K15-KRASG12D mouse model IL-27 promoted papilloma incidence. IL-27 induced CD11b cells with endothelin A receptor (ETAR)-positive phenotype. Thus, in SCC patients, Dibra et al showed that IL-27RA-positive cells in the tumor stroma are correlated with tumor de-differentiation (69).

Inflammatory traits in basal cell carcinomas. As approximately 2.8 million new patients are diagnosed with BCC only in the USA each year, it remains a major health issue (70). Several inflammatory-related pathways were found in BCC. Hence, one characteristic of BCC is the continuous activation of the Hedgehog pathway due to mutations in the tumorsuppressor gene patch (Ptch) that induces inactivation or due to mutation in Smoothened that leads to activation. These mutations were considered as good therapeutic target candidates combined with direct anti-inflammatory approaches. There have been clinical trials addressing drugs such as difluoromethylornithine, thymidine dinucleotide, retinoids, non-steroidal anti-inflammatory drugs, vitamin D3, and silibinin or even green and black tea components (71).

Another inflammatory-related pathway studied in BCC is the non-canonical NF- $\kappa \mathrm{B}$ pathway. This pathway is dependent on I $\mathrm{B}$ kinase $\alpha(\mathrm{IKK} \alpha)$, and Jia et al demonstrated that nuclear IKK $\alpha$ binds to the promoters of inflammatory factors. Moreover, it seems that it binds to a stem cell marker, leucine-rich repeat-containing $\mathrm{G}$-protein coupled receptor 5 (LGR5), which activates the STAT3 signaling pathway during tumorigenesis. By knockdown of IKK $\alpha$, tumor growth and the EMT process are inhibited proving that IKK $\alpha$ is an oncogenic transformation factor through stemness and inflammatory related gene activation; thus BCC progression is directly linked to the inflammatory microenvironment (72).

Another factor that promotes stemness in BCC is the transcription factor, SRY-related HMG-box family of transcription factors (Sox9). In a mouse model of BCC it was shown that Sox 9 is expressed at tumor initiation and that its expression is Wnt/ $\beta$-catenin-dependent. In this genetic model, Sox 9 deletion and constitutive activation of the Hedgehog signaling pathway abolished BCC initiation highlighting Sox9 involvement in stemness, ECM remodeling and de-differentiation within tumor development and metastasis (73).

In another mouse experimental model using SENCAR mice, inflammation was induced by UVB, and skin tumor initiation was studied. It was reported that protein tyrosine kinase 6 (PTK6) expression was increased upon UVB action. In $\mathrm{Ptk}^{+/+}$and $\mathrm{Ptk}^{-/-}$SENCAR mice exposed to UVB it was shown that in wild-type PTK6 $\left(\mathrm{Ptk}^{+/+}\right)$UVB induced increased inflammation and increased PTK6 expression in basal epithelial cells. This action was correlated with higher tumor frequency and tumor load compared to $\mathrm{Ptk}^{-/-}$mice. In human SCC the activation of PTK6 was also highlighted. It seems that PTK6 contributes to UVB-dependent inflammation further increasing tumorigenesis in skin (74).

In $\mathrm{BCC}$ patients there is a constant search of inflammatory-related immune cells that can prognosticate disease 
evolution and the focus falls on neutrophils, monocytes and lymphocytes. In a recent retrospective study in $<550$ patients white blood cells (WBCs), neutrophil and monocyte values were found decreased in the BCC group compared to controls. Neutrophil:lymphocyte ratios were found to be 3.24 in BCC and 3.59 in SCC, as compared to 5.06 in control group (75).

As NMSC is highly associated with UV excessive irradiation there are intensive studies regarding the association of vitamin D and skin cancer risk. The endocrine system and vitamin D are highly involved in inflammation, cell growth and differentiation (76). Vitamin D acts through binding to the vitamin D receptor (VDR). In a huge study reported by Lin $e t a l$, involving over 17,000 BCC cases compared to over 250,000 controls, 2 single-nucleotide polymorphisms (SNPs) at new loci were found related to BCC risk. The study pointed out that inherited common variations in VDR are linked to BCC development (77). Another study performed by Kaukinen et al, also in 2017, using an animal skin model, showed that MCs expressing VDR are involved in UV-mediated immunosuppression. VDR enhanced expression of CYP24A1 (a hydroxylase) that inactivates vitamin $\mathrm{D}_{3}$ metabolites. In normal skin, up to $2.9 \%$ of the MCs were CYP24A1 $1^{+}$, with a high percentage of CYP24A1 $1^{+} \mathrm{MCs}$ in $\mathrm{AK}, \mathrm{SCC}$ and $\mathrm{BCC}$. The finding that $\mathrm{CYP} 24 \mathrm{~A} 1^{+} \mathrm{MCs}$ in keratinocyte-derived skin cancers is increased warrants further study (78). Similarly in other organs, increased expression of CYP24A1 in skin could be correlated in murine models with inflammation and progressive fibrosis (79).

The process of tumorigenesis includes several additional processes such as neo-vascularization, tissue invasion, and metastasis. All of these processes rely on tissue remodeling where the urokinase system is highly involved. Rubina et al demonstrated in 2017 that as BCC is associated with keratinocyte hyper-proliferation, inflammatory cell migration, and angiogenesis-processes, increased urokinase plasminogen activator receptor (UPAR) expression was found in the tumor surrounding stroma in BCC. Hence the uPA system is a molecular network that sustains aggressive proliferation and tumor cell invasion (80). Another molecular system that favors inflammation and tissue remodeling upon tumorigenesis are MMPs. Their activation is involved in the degradation of the basement membrane in processes such as inflammation, wound healing, angiogenesis and carcinogenesis. In BCC, MMP1 and MMP9 expression was found to be associated with disease progression. Thus, low levels were detected in AK foci, while intense expression was found in different types of BCC (81).

Several anti-inflammatory compounds support the proof for the link of inflammation with tumorigenesis. Hence, naproxen, a known anti-inflammatory compound, has also anti-proliferative and pro-apoptotic action. Chaudhary et al used a mouse model of UVB-induced skin tumorigenesis where naproxen significantly inhibited both BCC and SCC. The inhibition was reflected on the lesion number and volume and the main reduction was for BCC-type tumors. The effects were associated with decreased PCNA and cyclin D1 expression, increased apoptosis and inflammation-related molecules (e.g., iNOS, COX-2 and nuclear NF-kBp65). Even remaining tumors after naproxen therapy displayed a lower aggressive potential, lower EMT marker expression (e.g., N-cadherin, vimentin, Snail and Twist) and enhanced E-cadherin expression (49).
Imiquimod is a TLR7 agonist, that addresses an inflammatory-derived receptor, and it has been approved for in situ SCC which was recently extended to superficial BCC with positive clinical results. These results show a treatment strategy that reduces inflammation and reduces tumorigenesis (82).

Classic anti-inflammatory compounds, such as aspirin or other nonsteroidal anti-inflammatory drugs (NSAIDs) have been tested in BCC. Collectively, data from 11 clinical studies showed a $10 \%$ risk reduction of $\mathrm{BCC}$ for patients using NSAIDs while the use of aspirin had a weaker association with the decreased risk. This report highlights that in humans NSAIDs can be used in high-risk populations to reduce BCC initiation (83).

In summary, clinical data related to NMSC show that anti-inflammatory therapeutic approaches can reduce significantly UVB-induced skin carcinogenesis.

\section{Inflammatory platform in melanoma: reshaping discoveries}

In the cellular flow of transforming a normal melanocyte into a tumor cell there are several stages that occur (Fig. 3). From benign nevi to a full blown tumor cell, genetic instability and a pro-inflammatory milieu can lead to tumorigenesis and metastasis. In the cellular microenvironment, immune cells and immune-related molecules have a definitive role in the inflammatory landscape. Although the typical studied cellular interface in a tumor is between CTLs and cancer cells, currently the contribution of other immune cells is widely recognized. These other immune cells build the complex immune response in cancer involving both tumor promotion and facilitating cancer progression (84). In some unpredictable cases, the clinical evolution of melanoma claim additional prognostic markers to identify early stage and high risk melanoma patients thus aiding in improving clinical surveillance strategies and therapy management (85). One of these additional biomarkers includes inflammatory immune cell infiltrate that depict the local antitumor response or could trigger a pro-tumoral path (86).

Cellular profiles of the inflammatory setting. The immune inflammatory infiltrate (IF) can be considered as a 'pro-inflammatory' phenotype with infiltrating cells and a cytokine pattern depending on immune activation. The existence of IF is generally a good prognostic marker, but the tumor milieu may lack immune cell infiltration as a consequence of immune system ignorance and therefore tumor resistance occurs impairing the favorable immune activation (84). For deciphering the correct role of IF, we must understand its diverse cellular composition comprising lymphoid cells (CTLs, Tregs, Th and B lymphocytes, NK cells) and myeloid cells (DCs, myeloid-derived suppressor cells and macrophages). Each cellular type imprints immunostimulatory or immunosuppressive effects within the tumor site. Thus, it becomes essential to also evaluate the functional status of IF within the tumor environment, in an equal measure with its presence or absence (84). Nevertheless, there is a large data panel regarding the prognostic value of IF in cutaneous melanoma but this subject remains controversial due to the heterogeneity of patient groups, study methods and tumor 


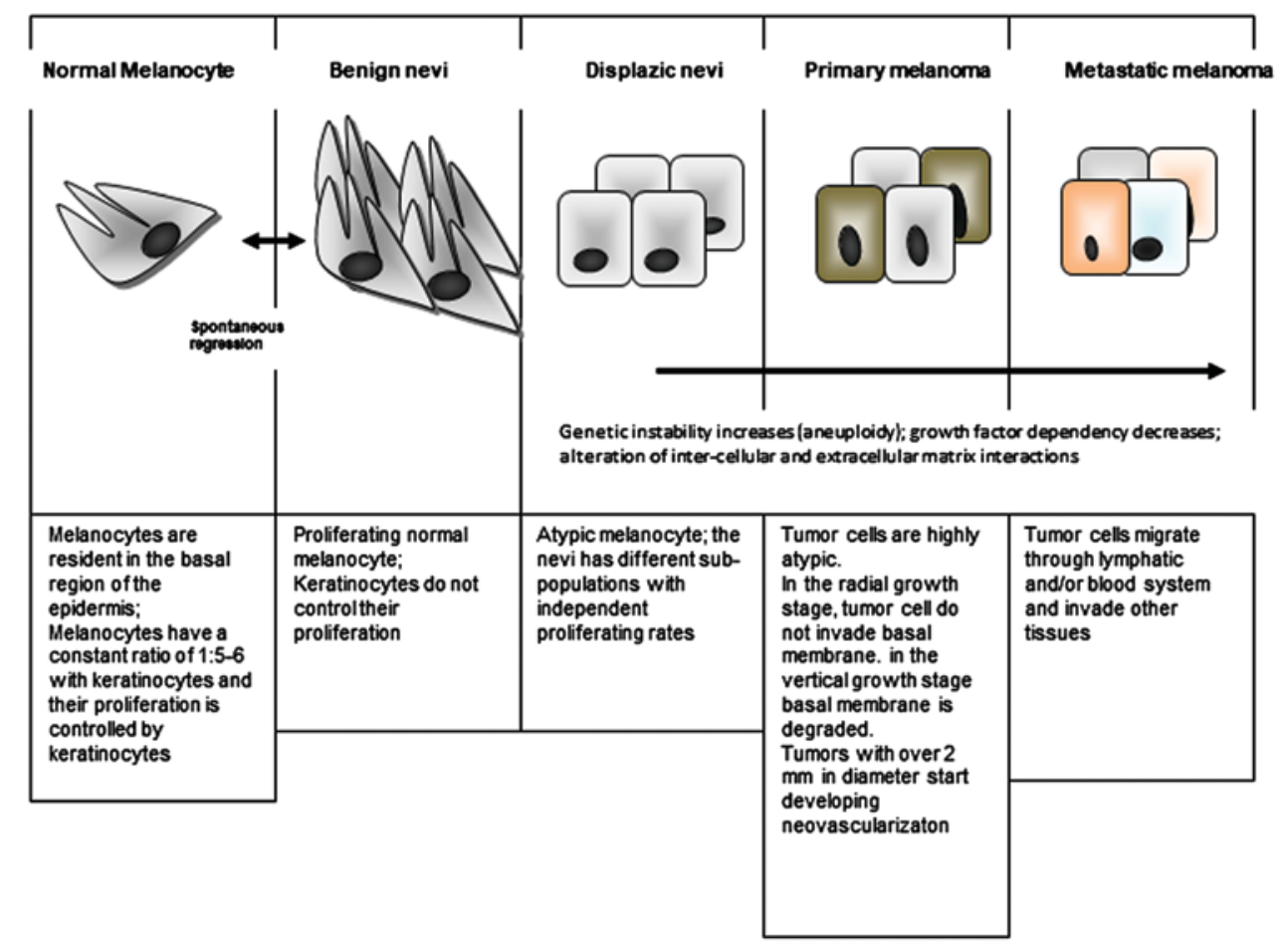

Figure 3. Normal melanocytes subjected to various factors that induce genetic instability and inflammatory conditions can undergo malignant transformation to melanoma.

infiltrating lymphocyte (TIL) classification systems. To date, no cancer staging algorithms integrate immune markers (85).

Myeloid cells in the tumor infiltrate: Antigen-presenting cells in skin

$D C s / L C s$. DCs play a critical role residing at the border between innate and adaptive immunity as specialized antigen-presenting cells, being important in tailoring immune reactivity, immune tolerance and activating antitumor immune response (87).

DCs are one of the immune cells relevant for melanoma antitumor immunity, having the potential to work as both targets and delivery agents for immunotherapies. Although recent immunotherapies do not directly involve DCs (e.g., immune checkpoint blockade and adoptive cellular transfer), they rely on DCs ability 'to shape the quality' of therapy-associated antitumor immune response. Moreover, tumor-associated DCs are decisive for improving melanoma immunotherapies as they are subjected to several processes specific for melanoma milieu: they are activated by immunogenic cellular death, could be suppressed by melanoma-associated factors, could suffer metabolic constraints or microbiome influences in mediating the anti-melanoma immune responses (88). Specific DCs in the skin immune network are represented by $\mathrm{LCs}\left(\mathrm{CD}^{+} \mathrm{a}^{+}\right.$, Langerin ${ }^{+}$, phenotypically mature, but functionally defective in melanoma-negative sentinel lymph nodes (SLNs) (89). In the last few years, the biology of LCs has considerably changed owing to novel insights in the developmental origin and functions of these epidermis-specific immune cells. LCs also have a significant impact on melanoma pathology by either inducing immune tolerance or mediating inflammatory processes (90). An important inference for the antitumor response is that LCs may activate more efficient naïve $\mathrm{CD}^{+} \mathrm{T}$ lymphocytes than dermal DCs (91).
The active role of LCs should be integrated in implementing or optimizing melanoma therapies. It was observed that LCs are remarkably radio-resistant cells in radiotherapy treated patients, and are highly potent in rapidly repairing DNA lesions through cyclin-dependent kinase inhibitor (CDKN1A) involvement. Such LC resistance has to be taken into account in light of new immunotherapies targeting melanoma, where it is pivotal to understand the immune cell dynamics within the tumor microenvironment (92).

LCs might also play a role in EMT in cutaneous cancers. One of the major regulators for LC activity is TGF- $\beta$ which also acts as a master controller of EMT processes in skin cancers (93). Another regulator for LCs is bone morphogenetic protein 7 (BMP7) responsible for a rested state of LCs in the epidermis. On the other hand, BMP7 induces mesenchymal to epithelial transition, thus acting as a homing signal to epithelia (94). E-cadherin expression loss occurring in EMT allows LCs to migrate out of the epidermis, produces $\beta$-catenin stabilization in various skin tumors and confers tolerogenicity of LCs (95). The migration of LCs from the skin to the lymph nodes is mediated through Met signaling, a receptor tyrosine kinase expressed on all DCs (96). In addition, Met signaling intercedes the enzymatic activity of MMP2 and MMP9 that are vital for LCs to break the basement membrane when migrating out of the epidermis (97).

In thin melanomas, the presence of LCs is associated with a better prognosis, by boosting antitumor defense through antigen presentation to $\mathrm{T} \mathrm{CD} 8^{+}$lymphocytes (98). Maturation phenotype of DCs can be a prognostic factor in cutaneous melanoma. The density of DCs expressing CDla and the maturation marker DC-LAMP in primary tumors were analyzed in melanoma cell nest infiltrates and in the surrounding stroma. Thus, infiltration of $\mathrm{CD}^{+} \mathrm{a}^{+} \mathrm{LAMP}^{+} \mathrm{DCs}$ was inversely 
correlated with the thickness of melanomas. High peritumoral density of mature CD1a $/$ DC-LAMP ${ }^{+}$DCs combined with high number of $\mathrm{CD} 25^{+} / \mathrm{OX} 40^{+} \mathrm{T}$ lymphocytes were associated with extended survival. A ratio of high mature DCs/high $\mathrm{OX} 40^{+} \mathrm{T}$ cells and Breslow index are reported as independent predictors of good prognosis and indicators of a functional immune response in primary cutaneous melanoma (99).

Myeloid-derived suppressor cells. Originated from bone marrow, myeloid-derived suppressor cells (MDSCs) are a subset of immune cells with myeloid origin and immunosuppressive properties, their development being modulated by different tumor-derived soluble factors (100). For example, certain factors released by melanoma cells induce changes in the phenotype of monocytes that are similar to monocytic (Mo)-MDSCs typical in advanced melanoma stages (101). Human MDSC populations can be grouped into Mo-MDSCs

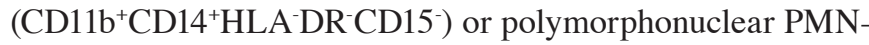

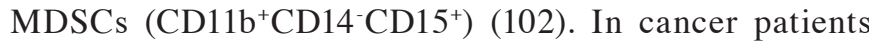
MDSCs are denoted as $\mathrm{CD}^{2} 3^{+} \mathrm{HLA}^{-} \mathrm{DR}^{-}$cells but in many studies, isolated MDSCs display several phenotypes in relation to the tumor sites. Thus, the phenotype (CD14 $\left.{ }^{+} \mathrm{HLA}^{-} \mathrm{DR}^{-}\right)$ was found to prevail in melanoma patients and moreover, in patients receiving ipilimumab there is no particular subset of MDSCs during melanoma progression (103). The MDSC phenotype $\left(\mathrm{CD} 11 \mathrm{~b}^{+} \mathrm{CD} 33^{+} \mathrm{CD} 14^{+} \mathrm{HLA}^{-} \mathrm{DR}^{-/ \mathrm{low}}\right)$ was reported to be elevated in the peripheral blood mononuclear cell (PBMC) population at melanoma onset and remain at comparable levels throughout disease progression (104). High levels of MDSCs were also associated with a lack of T lymphocyte clones specific for melanoma-derived antigens (105), providing a relevant clinical hint for correlation with patient survival. Thus, upon analyzing the $\mathrm{CD} 14^{+} \mathrm{HLA}^{-} \mathrm{DR}^{-/ \text {low }} \mathrm{MDSC}$ phenotype in stage II/III melanoma patients, it was found that low levels of these cells are associated with a tendency for an improved disease-free survival (106). In relation with other immune cell populations crucial for antitumor defense, it has been reported that in the cancer milieu, PMN-MDSCs exert suppressive activities on $\mathrm{CD}^{+} \mathrm{T}$ cells leading to a reduced proliferation and inhibition of IFN- $\gamma$ and IL-2 release by $\mathrm{T}$ cells (107). Moreover, in patients with advanced melanoma it was shown that both subsets of MDSCs suppress $\mathrm{CD}^{+} \mathrm{T}$ cell proliferation (108). The MDSC accumulation in various tumors has been associated with higher levels of IL-8 and several cytokines (IL-10, IL-13, IL-6) (104,109). Both monocytic and granulocytic MDSCs express IL-4R $\alpha$ that are associated with the suppressive activity of Mo-MDSCs in melanoma (110). Anther study focusing on various inflammatory markers suggested that levels of serum IL- $1 \beta$, IFN- $\gamma$ and CXCL10 were significantly increased in advanced melanoma and are direct correlated with increased MDSC and Treg populations; moreover, disease progression was associated with an increased serum concentration of IL-1 $\beta$ and CXCL10 (111). All these findings providing a strong foundation in identifying high risk patient groups based on circulatory profile of MDSCs, and developing therapeutic strategies relying on MDSC inhibition or even depletion in melanoma patients.

As in NMSC, in melanoma, inflammasomes have recently been given special attention as being directly linked to
IL-1 $\beta$-mediated tumorigenesis. In >200 melanoma tissue samples, increased expression of NLRP1 was found in the cytoplasm. After knocking down NLRP1 it was shown that several important molecules were downregulated, such as caspase- 1 activity, IL-1 $\beta$ production and secretion and nuclear factor- $\kappa \mathrm{B}$ activity that pointed out the NLRP1 inflammasomes role in the metastasis process. Therefore, Zhai et al showed that NLRP1 promotes melanoma tumorigenesis by activating inflammasomes and by suppressing apoptotic pathways (112).

Macrophages. Macrophages are myeloid cells $\left(\mathrm{CD}^{+} 8^{+}\right)$, with an essential role in inflammation and host defense; these cells are part of the innate immunity through their phagocytic capacity and also join the adaptive immunity by activating other immune cells via cytokine release. Macrophages may act in one of two polarized state, namely classically activated M1 macrophages and alternatively activated M2 macrophages. The M1 phenotype is pro-inflammatory (mostly activated by IFN- $\gamma$ ) while M2 macrophages release anti-inflammatory cytokines (IL-4, IL-10, TGF- $\beta$ ) and lean towards an anti-inflammatory or immunosuppressive profile (113). Their activity in one or the other polarized state in the tumor microenvironment affects melanoma progression and prognosis. Histopathological studies have shown that the macrophage polarization appears to be more connected to the presence of lymphocytic infiltrate than to the thickness of the melanoma lesions (114). A study performed in 94 cases of stages I-IV skin melanoma with a long follow-up duration depicts the correlation between M1/M2 phenotype and disease progression. Thus, by CD68 double immunostaining with MRP8-14 or iNOS (M1 phenotype) and with CD163 or CD204 (M2 phenotype) it was shown that in early melanoma stages, the M1 population was lower than the M2 population with a progressively increase in M2 cells during tumor progression. Thus, M1 cells shift to the M2 phenotype early in melanoma expansion, possibly induced by an intratumoral increase in iNOS. The intratumoral accumulation of both M1 and M2 is associated with poor prognostic indicators and patient survival, favoring neoplastic growth and dissemination (115).

In addition to polarized activation phenotypes, macrophages may be classified via their activation status in relation to the tumor. The inflammatory pattern of melanoma, with important diagnostic, prognostic and therapeutic biomarker power, resides in cell clones resembling tumor-associated macrophages. The inflammatory phenotype of macrophages is linked to Melan A expression loss from melanoma cells, a specific melanocyte marker (116). Lack of specific Melan A expression makes melanoma difficult to discriminate from tumors of mesenchymal origin. Morphological changes leading to mesenchymal outline and cellular de-differentiation are correlated with EMT and tumor dissemination. Events that govern EMT are driven by the inflammatory process and $\mathrm{CD}_{163}{ }^{+}$macrophages which induce E-cadherin and cell-to-cell adhesion loss as the final step of EMT completion. Melan A-negative clones in tumor tissues are correlated significantly with an increased inflammatory response elicited by tumor-infiltrating $\mathrm{CD} 63^{+}$macrophages, the complete loss of E-cadherin expression and a spindle-shaped morphology of tumor cells, altogether as possible markers of poor differentiation and tumor invasiveness (116). 
Lymphoid cells in tumor infiltrate T lymphocytes (cytotoxic, regulatory, helper). In evaluating the circulatory cellular immune pattern for a melanoma patient, a first step to be taken is testing the absolute count of lymphocytes which further provides specific data regarding circulating subpopulations. T lymphocyte subsets represent the most extensively studied immune cell populations in melanoma. These cells are both regulators and effectors of the antitumor immune response, and $\mathrm{CD} 8^{+} \mathrm{T}$ cells are often associated with a favorable clinical outcome (117). The pool of total $\mathrm{CD}^{+} \mathrm{T}$ lymphocytes is a parameter that will change throughout the patient follow-up only in advanced melanoma therefore calculating the $\mathrm{CD} 4^{+} / \mathrm{CD}^{+}$ $\mathrm{T}$ cells ratio will indicate the evolution of disease and will prognosticate the patient overall survival (OS) irrespective to melanoma stage and the received therapy. Other circulatory immune cells are found to be increased only in stage III when the $\mathrm{CD} 4^{+} \mathrm{CD} 69^{+}$phenotype indicates a lymph node-related antitumoral response; there are reports that claim that the proportion of circulating $\mathrm{CD}^{+} \mathrm{CD} 4^{+} \mathrm{CD} 69^{+}$cells evaluated before therapy administration can be an independent prognostic factor for OS (118). The influence of different phenotypes upon survival could be explained by the abundance of diverse $\mathrm{T}$ lymphocyte subsets, especially within $\mathrm{CD} 4^{+} \mathrm{Th}$ lymphocytes. The different profiles of T cells imprint different clinical responses according to their cytokine repertoire. Thus, cytokines related to the Th1 subset are strongly linked to positive clinical responses while the Treg $\left(\mathrm{CD} 4^{+} \mathrm{CD} 25^{\text {high }} \mathrm{CD} 127\right.$ Foxp $\left.^{+}\right)$cytokine panel is usually an indicator of a poor prognosis $(119,120)$. In metastatic melanoma a suppression of Th1 growth and a Th2 driven chronic inflammatory state, expressed in an increased Th2/Th1 ratio was reported. Moreover, if the Th1 subtype is dominant in patients with completely resected melanoma, in those with metastatic melanoma Th2 cells are the dominant subset sustained by tumor-derived VEGF. High levels of Th2-related cytokines (IL-4, IL-10, IL-13) and chemokines (CCL5, CXCL10) have been detected in plasma of metastatic melanoma patients (121-124).

As for the Treg phenotype, the proportion of peripheral Tregs were found to increase with disease stage but no correlation could be established with metastasis degree (125).

In less than 100 analyzed melanoma patients, it was found that the IF from regressed and non-regressed tumor area has a different distribution of inflammatory cells (126), mainly comprising $\mathrm{T}$ lymphocytes $\left(\mathrm{CD}^{+}\right)(127,128)$. A significant association between high $\mathrm{pT}$ level, $\mathrm{CD}^{+} \mathrm{T}$ cell frequency and ulceration was identified. Non-ulcerated tumors have similar distributions of $\mathrm{CD}^{+}$cells irrespective of $\mathrm{pT}$ level; ulceration cases present frequent $\mathrm{CD}^{+}$cells in association with high $\mathrm{pT}$ levels. Considering the overall favorable prognosis associated with active tumor infiltrating leukocytes (TILs) $(129,130)$, the presence of abundant TILs within thick ulcerated tumors represent a normal increasing of the IF as a physiologic reaction to ulceration (126).

$\mathrm{T} \mathrm{CD}^{+}$cells co-localize with major histocompatibility complex (MHC) class I expressed on the tumor cell surface in a pro-inflammatory setting, and with programmed death-ligand 1 (PD-L1), a critical immune checkpoint that exhibits an unfavorable prognostic impact in metastatic melanoma. In addition, PD-L1 expression on circulating $\mathrm{T}$ cells predicts a worse survival $(131,132)$. By blocking these critical molecules, a significant development in metastatic melanoma treatment has been achieved. Monitoring the efficacy of such an endeavor is based also on evaluating cellular immune population reinforced by the revolutionary therapy. For instance, in advanced melanoma, immunotherapy by pharmacologically blocking cytotoxic T-lymphocyte-associated antigen (CTLA)-4 on Tregs, can be monitored by an increase in circulating $\mathrm{CD}^{+}$and $\mathrm{CD}^{+} \mathrm{T}$ cell lymphocytes $(103,133)$. Immunotherapy endows the effector, killing functions of $\mathrm{T}$ cells for the patient benefit. Thus, $\mathrm{CD}^{+} \mathrm{T}$ cells exert tumoricidal functions through the expression of granzyme $\mathrm{B}$, and the activating markers CD25 and OX40, especially if T cells are present in peritumoral areas or primary tumor site when it associates with a better outcome (117).

The antitumoral activity of $\mathrm{CD} 4^{+} \mathrm{T}$ cells was investigated by analysis of membrane CD134 expression (OX40) and it was found that CD134 expression has been linked to a favorable outcome. Moreover the level of CD134 expression on $\mathrm{CD}^{+} \mathrm{T}$ cells in LNs append to primary melanomas declined with more advanced stage and LN involvement suggesting an immunosuppressive effect from tumor to LN location (134).

B lymphocytes. B cells frequently infiltrate the human tumor milieu and the higher numbers of CD20+ tumor B cells (TAB) are usually associated with a favorable prognosis. In human cutaneous primary melanomas, this interrelation is still controversial. Thus, in a recent study, the authors analyzed the association of TAB numbers and OS assessing CD20 immunohistochemistry on archival non-metastasized and metastasized primary melanoma tissues from 2 independent patient cohorts; survival association was validated with RNA data from a third independent cohort. The results of the study revealed the TAB number as a prognostic biomarker in patients with tumors of $>1 \mathrm{~mm}$ Breslow depth. Moreover, higher CD20/CD19 tumor mRNA levels were found to be associated with a significantly better OS (135). This report is in line with previous data that sustain the direct relation of infiltrating B cells and better prognosis (136). Another $\mathrm{B}$ cell phenotype, namely $\mathrm{CD} 138^{+}$plasmocytes are frequently reported in areas of regressed melanoma but their expression was regardless of regression or ulceration type (126). A subset of B-lymphocytes (B1 cells) with in vivo pro-metastatic properties was also identified and their presence was directly correlated with MCAM melanoma cell adhesion molecule (MUC18) (also known as CD146) expression in melanoma cells. Moreover, MUC18 expression can be therapeutically triggered in human melanoma, hampering the tumor invasion process (137). Reports related to advanced melanoma stages show statistically higher circulating CD $19^{+}$B lymphocytes with no increase in plasma level of total or immunoglobulin (Ig) subclasses. There is a negative correlation between the circulating B lymphocyte level and NK cells in melanoma patients (126), launching new insights in analysis of prognostic and predictive significance of lymphoid immune cell interrelation in cutaneous melanoma.

NK cells. NK cells are phenotypically defined as CD3-CD56 ${ }^{+}$ expressing the surface receptor NKp46 (CD335) distinctive for this cell population. In addition, human NK cells are subdivided into $\mathrm{CD}^{1} 6^{+} \mathrm{CD} 56^{\mathrm{dim}}$ (prevailing in blood), and $\mathrm{CD} 16^{-} \mathrm{CD} 56^{\text {bright }}$ 
subtypes (138). The role of NK cells in melanoma tumor inflammatory infiltration are currently not fully elucidated, representing an actual research topic (139). Different NK cell phenotypes are involved in organ specific susceptibility to melanoma metastasis. In an experimental murine model it was reported that immature $\mathrm{CD} 27^{+} \mathrm{CD} 11 \mathrm{~b}^{-} \mathrm{NK}$ cells protect liver from metastasis through a perforin-dependent cytotoxic mechanism against tumor, while at the pulmonary level, mature

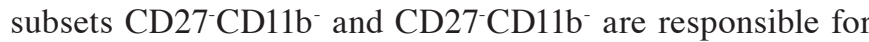
reducing tumor burden (140). $\mathrm{CD} 56^{\mathrm{dim}} \mathrm{CD} 57^{+}$activated cells exert their functions in spite of Treg cell presence. During melanoma progression, the $\mathrm{CD} 56^{\mathrm{dim}} \mathrm{CD} 57^{+} / \mathrm{CD} 56^{\text {bright }} \mathrm{CD} 57^{+}$ cell ratio increases and could be used as a prognostic marker (141).

The NK cells discriminate between normal and transformed cells sensing the insufficient level of MHC class I molecules expressed on latest ones (142). There is a bidirectional interaction between melanoma cells and NK cells as target recognition by NK depends on the interplay between killer activating (KAR) and killer inhibitory (KIR) receptors expressed on NK cells, and further by signals delivered to the tumor cell. Activated NK cells secrete factors (perforines, granzymes), express death mediating biomolecules (FasL/CD95 and TRAIL) and produce various cytokines (e.g., IFN- $\gamma$ ) that destroy the tumor target and also recruit other immune cells to the tumor site $(139,143)$.

An altered/decreased MHC class I expression on tumor cells is an escape mechanism by which melanomas avoid $\mathrm{CD}^{+}$ $\mathrm{T}$ cell attack but facilitate NK cell-mediated killing. This is the reason why melanoma is considered a model for the study of NK cell-mediated tumor killing (144). Recent studies report that a high percentage of melanoma cells hold ligands for NK activating receptors (e.g., NKG2D and DNAM1), and ligands for natural cytotoxicity receptors such as NKp30 (138). There is a process denominated as 'melanoma immunoediting' that leads to tumor escape from NK cell attack by multiple mechanisms such as increased expression of MHC-I, or downregulation of NK ligands especially in metastatic sites; the same inhibitory action upon NK cells is exerted by indole amine 2,3-dioxygenase (IDO) and PGE2 secreted by melanoma cells (145). Melanoma cells regulate NK lymphocytes via different cytokine/chemokine repertoire; thus, it was reported that IL-18 secreted by tumor cells upregulates PD-1 expression on NK cells (146). Also, it seems that melanoma metastatic evolution is associated with an increased frequency of peripheral NK cells expressing receptors for CXCL8, corroborated with CXCL8 released by tumor cells $(141,147)$. Moreover, it has been proposed that anti-IL-18 antibodies in combination with anti-PD-1 mAb (nivolumab) may avoid NK cell inhibition by PD-1 (148).

Recently, it was shown that melanoma-infiltrated lymph nodes contains twice as many NK cells compared with tumor-free nodes, and a population of highly cytotoxic NK cells $\left(\mathrm{CD} 56^{\mathrm{dim}} \mathrm{KIR}^{+} \mathrm{CCR} 7^{+}\right)$with potential prognostic value was identified in melanoma (141).

Existing cancer immunotherapies largely focus on $\mathrm{CD} 8^{+}$ $\mathrm{T}$ lymphocyte empowering, although NK cells are also cytotoxic and effector cells in antitumor defense. Personalized cancer therapies should integrate both $\mathrm{CD} 8^{+} \mathrm{T}$ cells in acquired immunity and NK cells in innate immunity as a strong weapon for precision targeting of tumors (149). NK cells are strongly accountable for enlarging the immunotherapeutic arsenal in melanoma. Besides the much studied immune checkpoint blockade of CTLA4, NK cells could be tackled from this point of view as one of the major checkpoints in NK cell activation is mediated by MHC class I specific KIR receptors. Presently, two antibodies directed to NK cell checkpoint blockade are under clinical development for melanoma therapy, namely, lirilumab (anti-KIR in combination with ipilimumab) and IPH2201 (anti-NKG2A) (139).

Some outlines regarding circulatory immune cells in the melanoma inflammatory setting could be drawn and a first conclusion is that there is no perfect match between circulating immune cells and tumor-associated ones, a still non-deciphered inconsistency (98). Furthermore, circulating immune cellspecific phenotypes are finely linked to the diagnosed stage of the melanoma; therefore, a single immune cell population cannot depict accurately the disease evolution. Hence circulatory immune cell subsets, displaying an activated and/or a suppressor phenotype would give the physician a more focused immune status of the patient for future personalized disease management.

\section{Inflammatory-related molecules in melanoma: the pattern of inflammatory molecules in melanoma tissue}

There is a clear immune suppressive environment developed at the tumor site where several inflammatory cells and molecules affect tumor development and invasiveness (32). Macrophages secrete IDO, an immunosuppressive enzyme, that induces inhibition of $\mathrm{T}$ cell proliferation due to tryptophan depletion and, moreover, IDO recruits more Tregs into the tumor area. As a consequence, TGF- $\beta$-secreting Tregs will induce suppression on the effector couple $\mathrm{CD} 4^{+} / \mathrm{CD}^{+}$diminishing the control on tumor development. Tumor cells also secrete TGF- $\beta$, IL-10, VEGF and PGE2 that induce DCs to release more TGF- $\beta$ contributing to the conversion of $\mathrm{CD} 4^{+} \mathrm{T}$ cells to a Treg phenotype and thus augmenting the cellular immune suppression. By a concerted action, a favorable microenvironment is created resulting in Treg proliferation that hinders the cooperation of $\mathrm{CD} 4^{+} / \mathrm{CD}^{+} \mathrm{T}$ cells and obliterates the antitumoral activity of cytotoxic cells. In addition, IDO is proposed as a prognostic and follow-up marker in melanoma. Thus, in a recent study IDO, lactate dehydrogenase (LDH) and S100B levels were measured in 186 serum samples from patients in all melanoma stages, at diagnosis and twice a year afterward. At diagnosis, serum IDO levels were significantly higher in stages IB, II, III and IV, whereas S100B levels were significantly higher in stages III and IV; as expected, LDH levels were higher only in stage IV. In relapsed patients, all three tested markers were found to be significantly increased. Finally, OS was significantly longer in patients with IDO levels below a certain cut-off value at diagnosis $(1.65 \mu \mathrm{M})$ than in those with higher IDO levels (91.3 vs. $71.0 \%$ at 36 months). These data indicate IDO as a potential useful serum prognostic biomarker for melanoma (150).

Circulatory inflammatory marker pattern in melanoma. The immune tolerance could rely on the initiation of the chronic inflammatory phase; thus, tumor cells could avoid the immune system because the pro-inflammatory status is diminished 
and switched to immunosuppression. This inflammatory status conversion is triggered by a wide variety of mediators. Thus, high levels of circulating biomolecules associated with poor prognosis in melanoma (TNFR2, TGF- $\alpha$, TIMP1, CRP) were recently identified by multiplex ELISA sandwich and proposed as being part of a valuable formulation for prediction of OS (151,152). Another study performed on stage II and III melanoma patients receiving IFN- $\alpha 2 b$ treatment point that the combination of serum TNF- $\alpha$, soluble IL-2 receptor and $\beta 2$ microglobulin could be robust predictive markers of melanoma relapse in relation to treatment. Increased serum levels of TNF- $\alpha$ seem to have a protective role before and despite high toxicity after IFN- $\alpha 2$ b treatment (153) but the prognostic value of TNF- $\alpha$ is still a matter of debate (154). In recent years new insights were gained regarding pro-inflammatory/antitumor vs. anti-inflammatory/protumoral effects of TNF- $\alpha$. It seems that membrane bound TNF- $\alpha$, rather than soluble TNF- $\alpha$, can activate MDSCs as an active part of tumor-related IF; stimulated MDSCs will release a whole cascade of mediators (ARG1, iNOS, NO, ROS, IL-10, TGF- $\beta$ ) that finally leads to a suppressed immune response against tumor (155). In this orchestrated action beside the soluble form of TNF it seems that membrane-bound TNFR2 is also involved (156). Moreover, TNFR2 is also expressed on a subset of Tregs sustaining the anti-inflammatory condition and tumor tolerance (157).

Although groundbreaking progress has been made in the last few years in terms of immunotherapies, the panel of circulatory reliable/validated markers for monitoring melanoma prognosis or staging still remains limited. Thus, LDH is the first serum biomarker included in 2001 by AJCC to be used for staging, prognosis and overall survival evaluation in melanoma stage IV patients (158). Moreover, LDH remains a clinically significant marker associated with response, progression-free survival, melanoma-specific survival (MSS) and $\mathrm{OS}$ in the new era of targeted and immunotherapies. At the 8th AJCC edition (2017), between several key changes it was included that an elevated LDH level no longer independently defines M1c disease "with or without M1a or M1b sites of disease' (159). The serum S100 calcium binding protein B (S100B) marker is also in process of validation and a recent study on a large cohort of non-resectable stage IV melanoma patients suggest S100B to be a better independent marker than LDH for long-term survival prediction. This could be explained by the non-specificity of the largely expressed LDH marker, released in the systemic circulation in many inflammatory disorders associated with cell lysis, as opposed to the more specific S100B, that is secreted by cells originated from the neural crest, including melanoma cells (160). Other recent data claim that $\mathrm{S} 100 \mathrm{~B}$ serum levels correlate with tumor load, response to treatment and might identify patients with increased risk of disease relapse; very important, S100B may predict prognosis independent to $\mathrm{LDH}$, and could act as an early biomarker of tumor recurrence (161). S100B was also connected to inflammation as it interacts with the activated leukocyte cell adhesion molecule (ALCAM) and mediates $\mathrm{NF}-\kappa \mathrm{B}$ signaling (162).

There is a strong correlation between S100B and melanoma inhibitory activity (MIA), a protein secreted by chondrocytes and melanoma cells, association that matches an unfavorable clinical evolution. Significant MIA increases were found to occur as early as stage II, with a better specificity and sensitivity when used together with S100B, correlating with immune parameters and having the potential of being biomarkers for prognosis and therapy monitoring (163). The increased MIA level in patients with poor prognosis could be a potential indicator of a pro-inflammatory status switching to a more anti-inflammatory and immunosuppressive phase of the disease (164).

Acute phase reactant proteins (APRPs) are usually produced by hepatocytes upon cytokine stimulation, and in a wide variety of diseases, including melanoma, a prolonged inflammation status leads to the persistence of APRP level changes. MALDI-TOF mass spectrometric analysis identified serum amyloid $\mathrm{A}$ as a valuable prognostic marker for all melanoma stages, with an increased specificity and sensitivity for early stages in combination with $\mathrm{C}$ reactive protein (CRP). These two acute phase proteins may have great clinical significance in melanoma considering also the cost efficiency of their in tandem testing (165).

The extensive diversity of soluble mediators and cells involved in the complex switch between acute and chronic inflammation could provide novel early indicators regarding tumor immunosuppressive status, induced by prolonged inflammation, and offer new insights in early diagnosis, prognosis evaluation and melanoma therapy monitoring.

\section{Conclusion}

Inflammation has a physiological important role as its final goal is tissue damage healing. When this process develops as chronic inflammation it triggers molecular and cellular networks that generate an immunosuppressive millieu, that can drive skin tumorigenesis. Various intrinsic and extrinsic factors can trigger the chronic status of inflammation, but the major initiating trigger in NMSC and melanoma skin cancers is photoaging. Disturbing factors alter the normal interactions between resident skin cells and immune cells that further alter tissue homeostasis.

It is extremely important in skin cancers to detect the molecular pathways that switch from acute to chronic inflammation because these pathways can be used as both predictors and markers as future therapy targets. The inflammatory status of the patients, whether related to the tissue and/or circulatory markers can aid the overall prognosis of the patient. Anti-inflammatory approaches, as already proven in NMSC are bringing new therapeutical tools to classical therapies.

Unveiling chronic inflammation patterns related to tumorigenesis can further direct/redirect the therapy choice and furnish identification of new target molecules (166). There are still questions to be answered, such as the link between sex steroid hormones and inflammation and the involvement of inflammation pattern in immunosuppressive mechanisms, but future research would further elucidate the inflammatory complex networks that should be driven towards antitumorigenic processes.

\section{Acknowledgements}

Not applicable. 


\section{Funding}

This manuscript was supported by grant no. PN-III-P1-1.2-PC CDI-2017-0341 and PN 18.21.02.02.

\section{Availability of data and materials}

The datasets used and/or analyzed during the current study are available from the corresponding author on reasonable request.

\section{Authors' contributions}

MN, CCo, CCa, CD, MS and SZ were responsible for data gathering, analysis and contributed to writing the manuscript and revising it critically for important intellectual content. All authors read and approved the final version of manuscript.

\section{Ethics approval and consent to participate}

Not applicable.

\section{Patient consent for publication}

Not applicable.

\section{Competing interests}

The authors declare that they have no competing interests.

\section{References}

1. Neagu M: The immune system: A hidden treasure for biomarker discovery in cutaneous melanoma. Adv Clin Chem 58: 89-140, 2012.

2. Boda D, Docea AO, Calina D, Ilie MA, Caruntu C, Zurac S Neagu M, Constantin C, Branisteanu DE, Voiculescu V, et al: Human papilloma virus: Apprehending the link with carcinogenesis and unveiling new research avenues (Review). Int J Oncol 52: 637-655, 2018.

3. Calleja-Agius J, Brincat M and Borg M: Skin connective tissue and ageing. Best Pract Res Clin Obstet Gynaecol 27: 727-740, 2013.

4. Fisher GJ, Kang S, Varani J, Bata-Csorgo Z, Wan Y, Datta S and Voorhees JJ: Mechanisms of photoaging and chronological skin aging. Arch Dermatol 138: 1462-1470, 2002.

5. Martinon F, Burns K and Tschopp J: The inflammasome: A molecular platform triggering activation of inflammatory caspases and processing of proIL- $\beta$. Mol Cell 10: 417-426, 2002

6. Sollberger G, Strittmatter GE, Grossi S, Garstkiewicz M, Auf dem Keller U, French LE and Beer HD: Caspase-1 activity is required for UVB-induced apoptosis of human keratinocytes. J Invest Dermatol 135: 1395-1404, 2015.

7. Ortiz ML, Kumar V, Martner A, Mony S, Donthireddy L, Condamine T, Seykora J, Knight SC, Malietzis G, Lee GH, et al: Immature myeloid cells directly contribute to skin tumor development by recruiting IL-17-producing $\mathrm{CD}^{+} \mathrm{T}$ cells. J Exp Med 212: 351-367, 2015

8. Awad F, Assrawi E, Louvrier C, Jumeau C, Giurgea I, Amselem S and Karabina SA: Photoaging and skin cancer: Is the inflammasome the missing link? Mech Ageing Dev 172: 131-137, 2018

9. DeNardo DG and Coussens LM: Inflammation and breast cancer. Balancing immune response: Crosstalk between adaptive and innate immune cells during breast cancer progression. Breast Cancer Res 9: 212, 2007.

10. Mantovani A, Allavena P, Sica A and Balkwill F: Cancer-related inflammation. Nature 454: 436-444, 2008.

11. Neagu M, Constantin C, Dumitrascu G, Lupu A, Caruntu C, Boda D and Zurac S: Inflammation markers in cutaneous melanoma-edgy biomarkers for prognosis. Discoveries (Craiova) 3: e38, 2015.
12. Lin WW and Karin M: A cytokine-mediated link between innate immunity, inflammation, and cancer. J Clin Invest 117: 1175-1183, 2007.

13. Neagu M, Constantin C, Manda G and Margaritescu I: Biomarkers of metastatic melanoma. Biomarkers Med 3: 71-89, 2009.

14. Mattii M, Lovászi M, Garzorz N, Atenhan A, Quaranta M, Lauffer F, Konstantinow A, Küpper M, Zouboulis CC, Kemeny L, et al: Sebocytes contribute to skin inflammation by promoting the differentiation of $\mathrm{T}$ helper 17 cells. Br J Dermatol 178: 722-730, 2018.

15. Neagu M, Caruntu C, Constantin C, Boda D, Zurac S, Spandidos DA and Tsatsakis AM: Chemically induced skin carcinogenesis: Updates in experimental models (Review). Oncol Rep 35: 2516-2528, 2016.

16. Martinon F: Dangerous liaisons: Mitochondrial DNA meets the NLRP3 inflammasome. Immunity 36: 313-315, 2012.

17. Feldmeyer L, Keller M, Niklaus G, Hohl D, Werner S and Beer HD: The inflammasome mediates UVB-induced activation and secretion of interleukin-1beta by keratinocytes. Curr Biol 17: 1140-1145, 2007.

18. Broz P and Dixit VM: Inflammasomes: Mechanism of assembly, regulation and signalling. Nat Rev Immunol 16: 407-420, 2016.

19. Kostyuk V, Potapovich A, Stancato A, De Luca C, Lulli D, Pastore S and Korkina L: Photo-oxidation products of skin surface squalene mediate metabolic and inflammatory responses to solar UV in human keratinocytes. PLoS One 7: e44472, 2012.

20. Oyewole AO and Birch-Machin MA: Sebum, inflammasomes and the skin: Current concepts and future perspective. Exp Dermatol 24: 651-654, 2015.

21. Ahmad I, Muneer KM, Chang ME, Nasr HM, Clay JM, Huang CC and Yusuf N: Ultraviolet radiation-induced downregulation of SERCA2 mediates activation of NLRP3 inflammasome in basal cell carcinoma. Photochem Photobiol 93: 1025-1033, 2017.

22. Latz E, Xiao TS and Stutz A: Activation and regulation of the inflammasomes. Nat Rev Immunol 13: 397-411, 2013.

23. Penuela S, Gyenis L, Ablack A, Churko JM, Berger AC, Litchfield DW, Lewis JD and Laird DW: Loss of pannexin 1 attenuates melanoma progression by reversion to a melanocytic phenotype. J Biol Chem 287: 29184-29193, 2012.

24. Zhong FL, Mamaï O, Sborgi L, Boussofara L, Hopkins R, Robinson K, Szeverényi I, Takeichi T, Balaji R, Lau A, et al: Germline NLRP1 mutations cause skin inflammatory and cancersusceptibility syndromes via inflammasome activation. Cell 167: 187-202, 2016.

25. Verma D, Bivik C, Farahani E, Synnerstad I, Fredrikson M, Enerbäck C, Rosdahl I and Söderkvist P: Inflammasome polymorphisms confer susceptibility to sporadic malignant melanoma. Pigment Cell Melanoma Res 25: 506-513, 2012.

26. Da Silva WC, Oshiro TM, de Sá DC, Franco DD, Festa Neto C and Pontillo A: Genotyping and differential expression analysis of inflammasome genes in sporadic malignant melanoma reveal novel contribution of CARD8, IL1B and IL18 in melanoma susceptibility and progression. Cancer Genet 209: 474-480, 2016.

27. Okamoto M, Liu W, Luo Y, Tanaka A, Cai X, Norris DA, Dinarello CA and Fujita M: Constitutively active inflammasome in human melanoma cells mediating autoinflammation via caspase-1 processing and secretion of interleukin-1 $\beta$. J Biol Chem 285: 6477-6488, 2010

28. Liu W, Luo Y, Dunn JH, Norris DA, Dinarello CA and Fujita M: Dual role of apoptosis-associated speck-like protein containing a CARD (ASC) in tumorigenesis of human melanoma. J Invest Dermatol 133: 518-527, 2013.

29. Drexler SK, Bonsignore L, Masin M, Tardivel A, Jackstadt R, Hermeking H, Schneider P, Gross O, Tschopp J and Yazdi AS: Tissue-specific opposing functions of the inflammasome adaptor ASC in the regulation of epithelial skin carcinogenesis. Proc Natl Acad Sci USA 109: 18384-18389, 2012.

30. Uhlén M, Fagerberg L, Hallström BM, Lindskog C, Oksvold P, Mardinoglu A, Sivertsson Å, Kampf C, Sjöstedt E, Asplund A, et al: Proteomics. Tissue-based map of the human proteome. Science 347: 1260419, 2015.

31. Gonda TA, Tu S and Wang TC: Chronic inflammation, the tumor microenvironment and carcinogenesis. Cell Cycle 8: 2005-2013, 2009.

32. Neagu M, Constantin C and Tanase C: Immune-related biomarkers for diagnosis/prognosis and therapy monitoring of cutaneous melanoma. Expert Rev Mol Diagn 10: 897-919, 2010 . 
33. Nedoszytko B, Sokołowska-Wojdyło M, RuckemannDziurdzińska K, Roszkiewicz J and Nowicki RJ: Chemokines and cytokines network in the pathogenesis of the inflammatory skin diseases: Atopic dermatitis, psoriasis and skin mastocytosis. Postepy Dermatol Alergol 31: 84-91, 2014.

34. Justus CR, Leffler N, Ruiz-Echevarria M and Yang LV: In vitro cell migration and invasion assays. J Vis Exp 1: 88, 2014.

35. Kong D, Li Y, Wang Z and Sarkar FH: Cancer stem cells and epithelial-to-mesenchymal transition (EMT)-phenotypic cells: Are they cousins or twins? Cancers (Basel) 3: 716-729, 2011

36. Plikus MV, Guerrero-Juarez CF, Treffeisen E and Gay DL: Epigenetic control of skin and hair regeneration after wounding. Exp Dermatol 24: 167-170, 2015

37. Yan C, Grimm WA, Garner WL, Qin L, Travis T, Tan N and Han YP: Epithelial to mesenchymal transition in human skin wound healing is induced by tumor necrosis factor- $\alpha$ through bone morphogenic protein-2. Am J Pathol 176: 2247-2258, 2010.

38. Leopold PL, Vincent J and Wang H: A comparison of epithelial-to-mesenchymal transition and re-epithelialization. Semin Cancer Biol 22: 471-483, 2012.

39. Egeblad M, Nakasone ES and Werb Z: Tumors as organs: Complex tissues that interface with the entire organism. Dev Cell 18: 884-901, 2010.

40. Kim Y and He YY: Ultraviolet radiation-induced non-melanoma skin cancer: Regulation of DNA damage repair and inflammation. Genes Dis 1: 188-198, 2014.

41. Pondicherry A, Martin R, Meredith I, Rolfe J, Emanuel P and Elwood M: The burden of non-melanoma skin cancers in Auckland, New Zealand. Australas J Dermatol 59: 210-213, 2018.

42. Avrămoiu I, Petrescu IO, Ciurea ME, Bold A, Siloşi I, ȚânŢu MM, Niculescu M, Anghel Savciu RE and Mogoantă SŞ: Peritumoral inflammatory reaction in non-melanoma skin cancers-histological and immunohistochemical study. Rom J Morphol Embryol 57: 943-950, 2016.

43. Nguyen AH, Detty SQ and Agrawal DK: Clinical implications of high-mobility group box-1 (HMGB1) and the receptor for advanced glycation end-products (RAGE) in cutaneous malignancy: A systematic review. Anticancer Res 37: 1-7, 2017.

44. Wu NL and Liu FT: The expression and function of galectins in skin physiology and pathology. Exp Dermatol 27: 217-226, 2018.

45. Kapucuoglu N, Basak PY, Bircan S, Sert S and Akkaya VB: Immunohistochemical galectin-3 expression in non-melanoma skin cancers. Pathol Res Pract 205: 97-103, 2009.

46. Nardinocchi L, Sonego G, Passarelli F, Avitabile S, Scarponi C, Failla CM, Simoni S, Albanesi C and Cavani A: Interleukin-17 and interleukin-22 promote tumor progression in human nonmelanoma skin cancer. Eur J Immunol 45: 922-931, 2015.

47. Von Schuckmann LA, Law MH, Montgomery GW, Green AC and Van Der Pols JC: Vitamin D pathway gene polymorphisms and keratinocyte cancers: A nested case-control study and meta-analysis. Anticancer Res 36: 2145-2152, 2016.

48. Dusingize JC, Olsen CM, Pandeya NP, Subramaniam P, Thompson BS, Neale RE, Green AC and Whiteman DC; QSkin Study: Cigarette smoking and the risks of basal cell carcinoma and squamous cell carcinoma. J Invest Dermatol 137: 1700-1708, 2017.

49. Chaudhary SC, Waseem M, Rana M, Xu H, Kopelovich L, Elmets CA and Athar M: Naproxen inhibits UVB-induced basal cell and squamous cell carcinoma development in Ptch $1^{+-} / \mathrm{SKH}-1$ hairless mice. Photochem Photobiol 93: 1016-1024, 2017.

50. Janda J, Burkett NB, Blohm-Mangone K, Huang V, Curiel-Lewandrowski C, Alberts DS, Petricoin EF III, Calvert VS, Einspahr J, Dong Z, et al: Resatorvid-based pharmacological antagonism of cutaneous TLR4 blocks UV-induced $\mathrm{NF}-\kappa \mathrm{B}$ and AP-1 signaling in keratinocytes and mouse skin. Photochem Photobiol 92: 816-825, 2016.

51. Matei C, Tampa M, Caruntu C, Ion RM, Georgescu SR, Dumitrascu GR, Constantin C and Neagu M: Protein microarray for complex apoptosis monitoring of dysplastic oral keratinocytes in experimental photodynamic therapy. Biol Res 47: 33-41, 2014.

52. Voiculescu V, Calenic B, Ghita M, Lupu M, Caruntu A, Moraru L, Voiculescu S, Ion A, Greabu M, Ishkitiev N, et al: From normal skin to squamous cell carcinoma: A quest for novel biomarkers. Dis Markers 2016: 4517492, 2016.

53. Voiculescu VM, Caruntu C, Solomon I, Lupu M, Ilie MA, Boda D, Constantin C and Neagu M: Squamous cell carcinoma: Biomarkers and potential therapeutic targets. In: Human Skin Cancers - Pathways, Mechanisms, Targets and Treatments. Blumenberg M (ed). IntechOpen, London, pp135-159, 2018.
54. Paulitschke V, Gerner C, Hofstätter E, Mohr T, Mayer RL, Pehamberger $\mathrm{H}$ and Kunstfeld R: Proteome profiling of keratinocytes transforming to malignancy. Electrophoresis 36: 564-576, 2015.

55. Farshchian M, Nissinen L, Siljamäki E, Riihilä P, Piipponen M, Kivisaari A, Kallajoki M, Grénman R, Peltonen J, Peltonen S, et al: Tumor cell-specific AIM2 regulates growth and invasion of cutaneous squamous cell carcinoma. Oncotarget 8: 45825-45836, 2017.

56. Muller HK and Woods GM: Ultraviolet radiation effects on the proteome of skin cells. Adv Exp Med Biol 990: 111-119, 2013

57. López-Camarillo C, Ocampo EA, Casamichana ML, Pérez-Plasencia C, Alvarez-Sánchez E and Marchat LA: Protein kinases and transcription factors activation in response to UV-radiation of skin: Implications for carcinogenesis. Int J Mol Sci 13: 142-172, 2012.

58. Bertrand-Vallery V, Boilan E, Ninane N, Demazy C, Friguet B, Toussaint O, Poumay Y and Debacq-Chainiaux F: Repeated exposures to UVB induce differentiation rather than senescence of human keratinocytes lacking p16(INK-4A). Biogerontology 11: $167-181,2010$.

59. Föll MC, Fahrner M, Gretzmeier C, Thoma K, Biniossek ML, Kiritsi D, Meiss F, Schilling O, Nyström A and Kern JS: Identification of tissue damage, extracellular matrix remodeling and bacterial challenge as common mechanisms associated with high-risk cutaneous squamous cell carcinomas. Matrix Biol 66: $1-21,2018$.

60. Guerra L, Odorisio T, Zambruno G and Castiglia D: Stromal microenvironment in type VII collagen-deficient skin: The ground for squamous cell carcinoma development. Matrix Biol 63: 1-10, 2017.

61. Meier K, Drexler SK, Eberle FC, Lefort K and Yazdi AS: Silencing of ASC in cutaneous squamous cell carcinoma. PLoS One 11: e0164742, 2016

62. Kirkley KS, Walton KD, Duncan C and Tjalkens RB: Spontaneous development of cutaneous squamous cell carcinoma in mice with cell-specific deletion of inhibitor of $\kappa \mathrm{B}$ kinase 2. Comp Med 67: 407-415, 2017.

63. Mohanan S, Horibata S, Anguish LJ, Mukai C, Sams K, McElwee JL, McLean D, Yan A and Coonrod SA: PAD2 overexpression in transgenic mice augments malignancy and tumor-associated inflammation in chemically initiated skin tumors. Cell Tissue Res 370: 275-283, 2017.

64. Atmatzidis DH, Lambert WC and Lambert MW: Langerhans cell: Exciting developments in health and disease. J Eur Acad Dermatol Venereol 31: 1817-1824, 2017.

65. Lin M, Sutherland DR, Horsfall W, Totty N, Yeo E, Nayar R, Wu XF and Schuh AC: Cell surface antigen CD109 is a novel member of the $\alpha(2)$ macroglobulin/C3, C4, C5 family of thioester-containing proteins. Blood 99: 1683-1691, 2002.

66. Sunagawa M, Mii S, Enomoto A, Kato T, Murakumo Y, Shiraki Y, Asai N, Asai M, Nagino M and Takahashi M: Suppression of skin tumorigenesis in CD109-deficient mice. Oncotarget 7: 82836-82850, 2016.

67. Varricchi G, Galdiero MR, Marone G, Granata F, Borriello F and Marone G: Controversial role of mast cells in skin cancers. Exp Dermatol 26: 11-17, 2017.

68. Latil M, Nassar D, Beck B, Boumahdi S, Wang L, Brisebarre A, Dubois C, Nkusi E, Lenglez S, Checinska A, et al: Cell-type-specific chromatin states differentially prime squamous cell carcinoma tumor-initiating cells for epithelial to mesenchymal transition. Cell Stem Cell 20: 191-204, 2017.

69. Dibra D, Mitra A, Newman M, Xia X, Keenan C, Cutrera JJ, Mathis JM, Wang XJ, Myers J and Li S: IL27 controls skin tumorigenesis via accumulation of ETAR-positive CD11b cells in the pre-malignant skin. Oncotarget 7: 77138-77151, 2016.

70. Ghita MA, Caruntu C, Rosca AE, Kaleshi H, Caruntu A, Moraru L, Docea AO, Zurac S, Boda D, Neagu M, et al: Reflectance confocal microscopy and dermoscopy for in vivo, non-invasive skin imaging of superficial basal cell carcinoma. Oncol Lett 11: 3019-3024, 2016.

71. Tilley C, Deep G and Agarwal R: Chemopreventive opportunities to control basal cell carcinoma: Current perspectives. Mol Carcinog 54: 688-697, 2015.

72. Jia J, Shi Y, Yan B, Xiao D, Lai W, Pan Y, Jiang Y, Chen L, Mao C, Zhou J, et al: LGR5 expression is controled by IKKa in basal cell carcinoma through activating STAT3 signaling pathway. Oncotarget 7: 27280-27294, 2016. 
73. Larsimont JC, Youssef KK, Sánchez-Danés A, Sukumaran V, Defrance M, Delatte B, Liagre M, Baatsen P, Marine JC, Lippens S, et al: Sox 9 controls self-renewal of oncogene targeted cells and links tumor initiation and invasion. Cell Stem Cell 17: 60-73, 2015.

74. Chastkofsky MI, Bie W, Ball-Kell SM, He YY and Tyner AL: Protein tyrosine kinase 6 regulates UVB-induced signaling and tumorigenesis in mouse skin. J Invest Dermatol 135: 2492-2501, 2015.

75. Baykan H, Cihan YB and Ozyurt K: Roles of white blood cells and subtypes as inflammatory markers in skin cancer. Asian Pac J Cancer Prev 16: 2303-2306, 2015.

76. Lupu M, Caruntu A, Caruntu C, Papagheorghe LML, Ilie MA, Voiculescu V, Boda D, Constantin C, Tanase C, Sifaki M, et al: Neuroendocrine factors: The missing link in non melanoma skin cancer (Review). Oncol Rep 38: 1327-1340, 2017.

77. Lin Y, Chahal HS, Wu W, Cho HG, Ransohoff KJ, Dai H, Tang JY, Sarin KY and Han J: Association between genetic variation within vitamin $\mathrm{D}$ receptor-DNA binding sites and risk of basal cell carcinoma. Int J Cancer 140: 2085-2091, 2017.

78. Kaukinen A, Siiskonen H, Pelkonen J and Harvima IT: Immunoreactivity to CYP24A1, but not vitamin D receptor is increased in mast cells of keratinocyte skin cancers. Eur J Dermatol 27: 590-598, 2017.

79. Weidenbusch M, Rodler S, Song S, Romoli S, Marschner JA, Kraft F, Holderied A, Kumar S, Mulay SR, Honarpisheh M, et al: Gene expression profiling of the Notch-AhR-IL22 axis at homeostasis and in response to tissue injury. Biosci Rep 37: BSR20170099, 2017. doi: 10.1042/BSR20170099.

80. Rubina KA, Sysoeva VY, Zagorujko EI, Tsokolaeva ZI, Kurdina MI, Parfyonova YV and Tkachuk VA: Increased expression of UPA, uPAR, and PAI-1 in psoriatic skin and in basal cell carcinomas. Arch Dermatol Res 309: 433-442, 2017.

81. Kuznetsova EV, Snarskaya ES, Zavalishina LE and Tkachenko SB: Immunohistochemical study of the specific features of expression of matrix metalloproteinases 1,9 in the photoaged skin, the foci of actinic keratosis and basal cell carcinoma. Arkh Patol 78: 17-22, 2016 (In Russian).

82. Papakostas D and Stockfleth E: Topical treatment of basal cell carcinoma with the immune response modifier imiquimod. Future Oncol 11: 2985-2990, 2015.

83. Muranushi C, Olsen CM, Green AC and Pandeya N: Can oral nonsteroidal antiinflammatory drugs play a role in the prevention of basal cell carcinoma? A systematic review and metaanalysis. J Am Acad Dermatol 74: 108-119.e1, 2016.

84. Barnes TA and Amir E: HYPE or HOPE: The prognostic value of infiltrating immune cells in cancer. Br J Cancer 117: 451-460, 2017

85. Weiss SA, Han SW, Lui K, Tchack J, Shapiro R, Berman R, Zhong J, Krogsgaard M, Osman I and Darvishian F: Immunologic heterogeneity of tumor-infiltrating lymphocyte composition in primary melanoma. Hum Pathol 57: 116-125, 2016.

86. Zurac S, Negroiu G, Andrei R, Petrescu S, Tebeica T, Petre M, Neagu M, Constantin C, Chitu V, Salavastru C, et al: Inflammatory infiltrate in melanoma with regression as prognostic parameter. Virchows Arch 463: 127, 2013.

87. Klechevsky E: Functional diversity of human dendritic cells Adv Exp Med Biol 850: 43-54, 2015.

88. Hargadon KM: Strategies to improve the efficacy of dendritic cell-based immunotherapy for melanoma. Front Immunol 8 : $1594,2017$.

89. Van de Ven R, van den Hout MF, Lindenberg JJ, Sluijter BJ, Van Leeuwen PA, Lougheed SM, Meijer S, Van den Tol MP, Scheper RJ and De Gruijl TD: Characterization of four conventional dendritic cell subsets in human skin-draining lymph nodes in relation to T-cell activation. Blood 118: 2502-2510, 2011

90. Deckers J, Hammad H and Hoste E: Langerhans cells: Sensing the environment in health and disease. Front Immunol 9: 93 2018.

91. Klechevsky E, Morita R, Liu M, Cao Y, Coquery S, Thompson-Snipes L, Briere F, Chaussabel D, Zurawski G, Palucka AK, et al: Functional specializations of human epidermal Langerhans cells and CD14 ${ }^{+}$dermal dendritic cells. Immunity 29: 497-510, 2008.

92. Price JG, Idoyaga J, Salmon H, Hogstad B, Bigarella CL, Ghaffari S, Leboeuf $\mathrm{M}$ and Merad M: CDKN1A regulates Langerhans cell survival and promotes Treg cell generation upon exposure to ionizing irradiation. Nat Immunol 16: 1060-1068, 2015.

93. Hieronymus T, Zenke M, Baek JH and Seré K: The clash of Langerhans cell homeostasis in skin: Should I stay or should I go? Semin Cell Dev Biol 41: 30-38, 2015.
94. Yasmin N, Bauer T, Modak M, Wagner K, Schuster C, Köffel R, Seyerl M, Stöckl J, Elbe-Bürger A, Graf D, et al: Identification of bone morphogenetic protein 7 (BMP7) as an instructive factor for human epidermal Langerhans cell differentiation. J Exp Med 210: 2597-2610, 2013.

95. Arwert EN, Hoste E and Watt FM: Epithelial stem cells, wound healing and cancer. Nat Rev Cancer 12: 170-180, 2012.

96. Baek JH, Birchmeier C, Zenke M and Hieronymus T: The HGF receptor/Met tyrosine kinase is a key regulator of dendritic cell migration in skin immunity. J Immunol 189: 1699-1707, 2012.

97. Yen JH, Khayrullina T and Ganea D: PGE2-induced metalloproteinase- 9 is essential for dendritic cell migration. Blood 111 260-270, 2008

98. Haanen JB, Baars A, Gomez R, Weder P, Smits M, De Gruijl TD, Von Blomberg BM, Bloemena E, Scheper RJ, Van Ham SM, et al: Melanoma-specific tumor-infiltrating lymphocytes but not circulating melanoma-specific $T$ cells may predict survival in resected advanced-stage melanoma patients. Cancer Immunol Immunother 55: 451-458, 2006.

99. Ladányi A, Kiss J, Somlai B, Gilde K, Fejos Z, Mohos A, Gaudi I and Tímár J: Density of DC-LAMP ${ }^{+}$mature dendritic cells in combination with activated $\mathrm{T}$ lymphocytes infiltrating primary cutaneous melanoma is a strong independent prognostic factor. Cancer Immunol Immunother 56: 1459-1469, 2007.

100.Dai J, El Gazzar M, Li GY, Moorman JP and Yao ZQ Myeloid-derived suppressor cells: Paradoxical roles in infection and immunity. J Innate Immun 7: 116-126, 2015.

101. Mao Y, Poschke I, Wennerberg E, Pico de Coaña Y, Egyhazi Brage S, Schultz I, Hansson J, Masucci G, Lundqvist A and Kiessling R: Melanoma-educated $\mathrm{CD} 14^{+}$cells acquire a myeloid-derived suppressor cell phenotype through COX-2-dependent mechanisms. Cancer Res 73: 3877-3887, 2013.

102. Bronte V, Brandau S, Chen SH, Colombo MP, Frey AB, Greten TF, Mandruzzato S, Murray PJ, Ochoa A, Ostrand-Rosenberg S, et al: Recommendations for myeloid-derived suppressor cell nomenclature and characterization standards. Nat Commun 7: 12150, 2016

103. Tarhini AA, Edington H, Butterfield LH, Lin Y, Shuai Y, Tawbi H, Sander C, Yin Y, Holtzman M, Johnson J, et al: Immune monitoring of the circulation and the tumor microenvironment in patients with regionally advanced melanoma receiving neoadjuvant ipilimumab. PLoS One 9: e87705, 2014.

104. Rudolph BM, Loquai C, Gerwe A, Bacher N, Steinbrink $\mathrm{K}$, Grabbe $\mathrm{S}$ and Tuettenberg A: Increased frequencies of

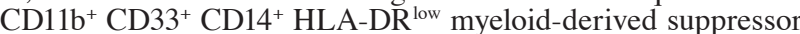
cells are an early event in melanoma patients. Exp Dermatol 23: 202-204, 2014

105. Martens A, Zelba H, Garbe C, Pawelec G and Weide B: Monocytic myeloid-derived suppressor cells in advanced melanoma patients: Indirect impact on prognosis through inhibition of tumor-specific T-cell responses? OncoImmunology 3: e27845, 2014.

106. Filipazzi P, Pilla L, Mariani L, Patuzzo R, Castelli C, Camisaschi C, Maurichi A, Cova A, Rigamonti G, Giardino F, et al: Limited induction of tumor cross-reactive $\mathrm{T}$ cells without a measurable clinical benefit in early melanoma patients vaccinated with human leukocyte antigen class I-modified peptides. Clin Cancer Res 18: 6485-6496, 2012.

107. Brandau S, Trellakis S, Bruderek K, Schmaltz D, Steller G, Elian M, Suttmann H, Schenck M, Welling J, Zabel P, et al: Myeloid-derived suppressor cells in the peripheral blood of cancer patients contain a subset of immature neutrophils with impaired migratory properties. J Leukoc Biol 89: 311-317, 2011

108. Schilling B, Sucker A, Griewank K, Zhao F, Weide B, Görgens A, Giebel B, Schadendorf D and Paschen A: Vemurafenib reverses immunosuppression by myeloid derived suppressor cells. Int J Cancer 133: 1653-1663, 2013.

109. Ene CD, Anghel AE, Neagu M and Nicolae I: 25-OH Vitamin D and interleukin-8 emerging biomarkers in cutaneous melanoma development and progression. Mediators Inflam 2015: 1-8, 2015.

110. Mandruzzato S, Solito S, Falisi E, Francescato S, Chiarion-Sileni V, Mocellin S, Zanon A, Rossi CR, Nitti D, Bronte $\mathrm{V}$, et al: IL4R $\alpha^{+}$myeloid-derived suppressor cell expansion in cancer patients. J Immunol 182: 6562-6568, 2009.

111. Jiang H, Gebhardt C, Umansky L, Beckhove P, Schulze TJ, Utikal J and Umansky V: Elevated chronic inflammatory factors and myeloid-derived suppressor cells indicate poor prognosis in advanced melanoma patients. Int J Cancer 136: 2352-2360, 2015. 
112.Zhai Z, Liu W, Kaur M, Luo Y, Domenico J, Samson JM, Shellman YG, Norris DA, Dinarello CA, Spritz RA, et al: NLRP1 promotes tumor growth by enhancing inflammasome activation and suppressing apoptosis in metastatic melanoma. Oncogene 36: 3820-3830, 2017.

113. Lopes RL, Borges TJ, Araújo JF, Pinho NG, Bergamin LS, Battastini AM, Muraro SP, Souza AP, Zanin RF and Bonorino C: Extracellular mycobacterial DnaK polarizes macrophages to the M2-like phenotype. PLoS One 9: e113441, 2014.

114. Scali E, Mignogna C, Di Vito A, Presta I, Camastra C, Donato G and Bottoni U: Inflammation and macrophage polarization in cutaneous melanoma: Histopathological and immunohistochemical study. Int J Immunopathol Pharmacol 29: 715-719, 2016.

115. Falleni M, Savi F, Tosi D, Agape E, Cerri A, Moneghini L and Bulfamante GP: M1 and M2 macrophages' clinicopathological significance in cutaneous melanoma. Melanoma Res 27: 200-210, 2017

116. Bønnelykke-Behrndtz ML, Steiniche T, Damsgaard TE Georgsen JB, Danielsen A, Bastholt L, Møller HJ, Nørgaard PH and Schmidt $\mathrm{H}$ : MelanA-negative spindle-cell associated melanoma, a distinct inflammatory phenotype correlated with dense infiltration of CD163 macrophages and loss of E-cadherin. Melanoma Res 25: 113-118, 2015.

117. Jacquelot N, Pitt JM, Enot DP, Roberti MP, Duong CPM, Rusakiewicz S, Eggermont AM and Zitvogel L: Immune biomarkers for prognosis and prediction of responses to immune checkpoint blockade in cutaneous melanoma. OncoImmunology 6: e1299303, 2017.

118. Hernberg M, Mattila PS, Rissanen M, Hansson J, Aamdal S, Bastholt L, Von der Maase H, Schmidt H, Stierner U and Tarkkanen J: The prognostic role of blood lymphocyte subset distribution in patients with resected high-risk primary or regionally metastatic melanoma. J Immunother 30: 773-779, 2007.

119. Fridman WH, Galon J, Pagès F, Tartour E, Sautès-Fridman C and Kroemer G: Prognostic and predictive impact of intra- and peritumoral immune infiltrates. Cancer Res 71: 5601-5605, 2011.

120. Jacobs JFM, Nierkens S, Figdor CG, de Vries IJM and Adema GJ: Regulatory $\mathrm{T}$ cells in melanoma: The final hurdle towards effective immunotherapy? Lancet Oncol 13: e32-e42, 2012.

121. Nevala WK, Vachon CM, Leontovich AA, Scott CG, Thompson MA and Markovic SN: Melanoma study group of the Mayo Clinic Cancer Center: Evidence of systemic Th2-driven chronic inflammation in patients with metastatic melanoma. Clin Cancer Res 15: 1931-1939, 2009.

122. Umansky V and Sevko A: Melanoma-induced immunosuppression and its neutralization. Semin Cancer Biol 22: 319-326, 2012.

123. Burkholder B, Huang RY, Burgess R, Luo S, Jones VS, Zhang W, Lv ZQ, Gao CY, Wang BL, Zhang YM, et al: Tumor-induced perturbations of cytokines and immune cell networks. Biochim Biophys Acta 1845: 182-201, 2014.

124. Neagu M, Constantin C and Longo C: Chemokines in the melanoma metastasis biomarkers portrait. J Immunoassay Immunochem 36: 559-566, 2015.

125. Wang W, Edington HD, Rao UN, Jukic DM, Radfar A, Wang H and Kirkwood JM: Effects of high-dose IFN $\alpha 2 b$ on regional lymph node metastases of human melanoma: Modulation of STAT5, FOXP3, and IL-17. Clin Cancer Res 14: 8314-8320, 2008.

126. Neagu M, Constantin $\mathrm{C}$ and Zurac S: Immune parameters in the prognosis and therapy monitoring of cutaneous melanoma patients: Experience, role, and limitations. BioMed Res Int 2013: 107940, 2013

127. Nguyen LT, Yen PH, Nie J, Liadis N, Ghazarian D, Al-Habeeb A, Easson A, Leong W, Lipa J, McCready D, et al: Expansion and characterization of human melanoma tumor-infiltrating lymphocytes (TILs). PLoS One 5: e13940, 2010.

128. Hussein MR, Elsers DA, Fadel SA and Omar AE: Immunohistological characterisation of tumour infiltrating lymphocytes in melanocytic skin lesions. J Clin Pathol 59: 316-324, 2006.

129. Azimi F, Scolyer RA, Rumcheva P, Moncrieff M, Murali R, McCarthy SW, Saw RP and Thompson JF: Tumor-infiltrating lymphocyte grade is an independent predictor of sentinel lymph node status and survival in patients with cutaneous melanoma. J Clin Oncol 30: 2678-2683, 2012.

130. Burton AL, Roach BA, Mays MP, Chen AF, Ginter BA, Vierling AM, Scoggins CR, Martin RC, Stromberg AJ, Hagendoorn L, et al: Prognostic significance of tumor infiltrating lymphocytes in melanoma. Am Surg 77: 188-192, 2011.
131. Kluger HM, Zito CR, Barr ML, Baine MK, Chiang VL, Sznol M, Rimm DL, Chen L and Jilaveanu LB: Characterization of PD-L1 expression and associated T-cell infiltrates in metastatic melanoma samples from variable anatomic sites. Clin Cancer Res 21: 3052-3060, 2015.

132. Ancuceanu $\mathrm{R}$ and Neagu M: Immune based therapy for melanoma. Indian J Med Res 143: 135-144, 2016.

133. Ménard C, Ghiringhelli F, Roux S, Chaput N, Mateus C, Grohmann U, Caillat-Zucman S, Zitvogel L and Robert C: Ctla-4 blockade confers lymphocyte resistance to regulatory T-cells in advanced melanoma: Surrogate marker of efficacy of tremelimumab? Clin Cancer Res 14: 5242-5249, 2008.

134. Sarff M, Edwards D, Dhungel B, Wegmann KW, Corless C, Weinberg AD and Vetto JT: OX40 (CD134) expression in sentinel lymph nodes correlates with prognostic features of primary melanomas. Am J Surg 195: 621-625, 2008.

135. Garg K, Maurer M, Griss J, Brüggen MC, Wolf IH, Wagner C, Willi N, Mertz KD and Wagner SN: Tumor-associated B cells in cutaneous primary melanoma and improved clinical outcome. Hum Pathol 54: 157-164, 2016.

136. Chiou SH, Sheu BC, Chang WC, Huang SC and Hong-Nerng H: Current concepts of tumor-infiltrating lymphocytes in human malignancies. J Reprod Immunol 67: 35-50, 2005.

137. Staquicini FI, Tandle A, Libutti SK, Sun J, Zigler M, Bar-Eli M, Aliperti F, Pérez EC, Gershenwald JE, Mariano M, et al: A subset of host B-lymphocytes control melanoma metastasis through a MCAM/MUC18-dependent interaction: Evidence from mice and humans. Cancer Res 68: 8419-8428, 2008.

138. Sadozai H, Gruber T, Hunger RE and Schenk M: Recent successes and future directions in immunotherapy of cutaneous melanoma. Front Immunol 8: 1617, 2017.

139. Tarazona R, Duran E and Solana R: Natural killer cell recognition of melanoma: New clues for a more effective immunotherapy. Front Immunol 6: 649, 2016.

140. Ballas ZK, Buchta CM, Rosean TR, Heusel JW and Shey MR: Role of NK cell subsets in organ-specific murine melanoma metastasis. PLoS One 8: e65599, 2013.

141. Ali TH, Pisanti S, Ciaglia E, Mortarini R, Anichini A, Garofalo C, Tallerico R, Santinami M, Gulletta E, Ietto C, et al: Enrichment of $\mathrm{CD} 56^{\mathrm{dim}} \mathrm{KIR}^{+} \mathrm{CD} 57^{+}$highly cytotoxic NK cells in tumour-infiltrated lymph nodes of melanoma patients. Nat Commun 5: 5639, 2014

142. Nielsen N, Ødum N, Ursø B, Lanier LL and Spee P: Cytotoxicity of CD56 $6^{\text {bright }} \mathrm{NK}$ cells towards autologous activated CD4 ${ }^{+} \mathrm{T}$ cells is mediated through NKG2D, LFA-1 and TRAIL and dampened via CD94/NKG2A. PLoS One 7: e31959, 2012.

143. Morvan MG and Lanier LL: NK cells and cancer: You can teach innate cells new tricks. Nat Rev Cancer 16: 7-19, 2016.

144. Mendez R, Aptsiauri N, Del Campo A, Maleno I, Cabrera T, Ruiz-Cabello F, Garrido F and Garcia-Lora A: HLA and melanoma: Multiple alterations in HLA class I and II expression in human melanoma cell lines from ESTDAB cell bank. Cancer Immunol Immunother 58: 1507-1515, 2009.

145. Baumeister SH, Freeman GJ, Dranoff G and Sharpe AH: Coinhibitory pathways in immunotherapy for cancer. Annu Rev Immunol 34: 539-573, 2016.

146. Terme M, Ullrich E, Aymeric L, Meinhardt K, Desbois M, Delahaye N, Viaud S, Ryffel B, Yagita H, Kaplanski G, et al: IL-18 induces PD-1-dependent immunosuppression in cancer. Cancer Res 71: 5393-5399, 2011

147. Singh S, Singh AP, Sharma B, Owen LB and Singh RK: CXCL8 and its cognate receptors in melanoma progression and metastasis. Future Oncol 6: 111-116, 2010.

148. Gras Navarro A, Bjorklund AT and Chekenya M: Therapeutic potential and challenges of natural killer cells in treatment of solid tumors. Front Immunol 6: 202, 2015.

149. Rosenberg J and Huang J: CD $8^{+}$T cells and NK cells: Parallel and complementary soldiers of immunotherapy. Curr Opin Chem Eng 19: 9-20, 2018.

150. De Lecea MV, Palomares T, Al Kassam D, Cavia M, Geh JLC, De Llano P, Muñiz P, Armesto D, Martinez-Indart L and Alonso-Varona A: Indoleamine 2,3 dioxygenase as a prognostic and follow-up marker in melanoma. A comparative study with LDH and S100B. J Eur Acad Dermatol Venereol 31: 636-642, 2017.

151. Tarhini AA, Lin Y, Yeku O, LaFramboise WA, Ashraf M, Sander C, Lee S and Kirkwood JM: A four-marker signature of TNF-RII, TGF- $\alpha$, TIMP-1 and CRP is prognostic of worse survival in high-risk surgically resected melanoma. J Transl Med 12: 19, 2014 
152.Zurac S, Neagu M, Constantin C, Cioplea M, Nedelcu R, Bastian A, Popp C, Nichita L, Andrei R, Tebeica T, et al: Variations in the expression of TIMP1, TIMP2 and TIMP3 in cutaneous melanoma with regression and their possible function as prognostic predictors. Oncol Lett 11: 3354-3360, 2016.

153. Hofmann MA, Kiecker F, Küchler I, Kors C and Trefzer U: Serum TNF- $\alpha$, B2M and sIL-2R levels are biological correlates of outcome in adjuvant IFN- $\alpha 2 b$ treatment of patients with melanoma. J Cancer Res Clin Oncol 137: 455-462, 2011.

154. Porter GA, Abdalla J, Lu M, Smith S, Montgomery D, Grimm E, Ross MI, Mansfield PF, Gershenwald JE and Lee JE: Significance of plasma cytokine levels in melanoma patients with histologically negative sentinel lymph nodes. Ann Surg Oncol 8: 116-122, 2001.

155. Hu X, Li B, Li X, Zhao X, Wan L, Lin G, Yu M, Wang J, Jiang X, Feng W, et al: Transmembrane TNF- $\alpha$ promotes suppressive activities of myeloid-derived suppressor cells via TNFR2. J Immunol 192: 1320-1331, 2014.

156.Polz J, Remke A, Weber S, Schmidt D, Weber-Steffens D, Pietryga-Krieger A, Müller N, Ritter U, Mostböck S and Männel DN: Myeloid suppressor cells require membrane TNFR2 expression for suppressive activity. Immun Inflamm Dis 2: 121-130, 2014.

157. Chen X and Oppenheim JJ: TNF- $\alpha$ : An activator of CD4 ${ }^{+}$Fox P $3{ }^{+} \mathrm{TNFR}^{+}{ }^{+}$regulatory $\mathrm{T}$ cells. Curr Dir Autoimmun 11: 119-134, 2010.

158. Balch CM, Buzaid AC, Soong SJ, Atkins MB, Cascinelli N, Coit DG, Fleming ID, Gershenwald JE, Houghton A Jr, Kirkwood JM, et al: Final version of the American Joint Committee on cancer staging system for cutaneous melanoma. J Clin Oncol 19: 3635-3648, 2001.

159. Gershenwald JE, Scolyer RA, Hess KR, Sondak VK, Long GV, Ross MI, Lazar AJ, Faries MB, Kirkwood JM, McArthur GA, et al: Melanoma staging: Evidence-based changes in the American Joint Committee on cancer eighth edition cancer staging manual. CA Cancer J Clin 67: 472-492, 2017.
160. Weide B, Richter S, Büttner P, Leiter U, Forschner A, Bauer J, Held L, Eigentler TK, Meier F and Garbe C: Serum S100B, lactate dehydrogenase and brain metastasis are prognostic factors in patients with distant melanoma metastasis and systemic therapy. PLoS One 8: e81624, 2013.

161. Karonidis A, Mantzourani M, Gogas H and Tsoutsos D: Serum S100B levels correlate with stage, N status, mitotic rate and disease outcome in melanoma patients independent to LDH. J BUON 22: 1296-1302, 2017

162. Von Bauer R, Oikonomou D, Sulaj A, Mohammed S, Hotz-Wagenblatt A, Gröne HJ, Arnold B, Falk C, Luethje D, Erhardt A, et al: CD166/ALCAM mediates proinflammatory effects of S100B in delayed type hypersensitivity. J Immunol 191: 369-377, 2013

163. Dumitraşcu G, Constantin C, Manda G, Hristescu S, Mărgaritescu I, Chiriţă D and Neagu M: Serum markers in skin melanoma-preliminary study. Roum Arch Microbiol Immunol 68: 125-135, 2009.

164. Schmidt J, Riechers A, Stoll R, Amann T, Fink F, Spruss T, Gronwald W, König B, Hellerbrand C and Bosserhoff AK: Targeting melanoma metastasis and immunosuppression with a new mode of melanoma inhibitory activity (MIA) protein inhibition. PLoS One 7: e37941, 2012.

165. Findeisen P, Zapatka M, Peccerella T, Matzk H, Neumaier M, Schadendorf D and Ugurel S: Serum amyloid A as a prognostic marker in melanoma identified by proteomic profiling. J Clin Oncol 27: 2199-2208, 2009.

166. Neagu $\mathrm{M}$ and Constantin C: Immune-therapy in cutaneous melanoma-efficacy immune markers. In: Advancements in Tumor Immunotherapy and Cancer Vaccines. Arnouk H (ed). InTech, Rijeka, Croatia, pp83-106, 2012.

This work is licensed under a Creative Commons Attribution-NonCommercial-NoDerivatives 4.0 International (CC BY-NC-ND 4.0) License. 